\title{
CONSTRUYENDO UN PAISAJE INKA: LA CONVERSIÓN DE LOS CENTROS CEREMONIALESY LA CONSTITUCIÓN DE LA AUTORIDAD DURANTE LA FORMACIÓN DEL ESTADO INKAIKO (CUSCO, PERÚ)
}

\author{
Steve Kosiba, Ph.D. \\ Departamento de ANTRopología, Universidad de Alabama \\ sbkosiba@as.va.edu \\ Vicentina GaLiano Blanco \\ MINISTERIO DE CULTURA, CUSCO \\ vikig7@hotmail.com
}

\section{RESUMEN}

En el artículo se presentarán datos arqueológicos recientes de prospecciones y excavaciones realizadas en el área de Ollantaytambo, para examinar cómo los grupos sociales de la región del Cusco fueron incorporados al Estado inka. En particular, se analizará como los Inkas afirmaron su autoridad transformando el paisaje de la región, remodelando la arquitectura de lugares ceremoniales preexistentes y regulando las actividades rituales tradicionales, lo que conlleva un cuestionamiento de las teorías predominantes sobre la formación del Estado inka.

Palabras Clave: Paisaje, Sistema de Información Geográfica, Inka, Periodo Intermedio Tardío, Cusco.

\section{Abstract}

En el artículo se presentarán datos arqueológicos recientes de prospecciones y excavaciones realizadas en el área de Ollantaytambo, para examinar cómo los grupos sociales de la región del Cusco fueron incorporados al Estado inca. En particular, se analizará como los Incas afirmaron su autoridad transformando el paisaje de la región, remodelando la arquitectura de lugares ceremoniales preexistentes y regulando las actividades rituales tradicionales, lo que conlleva un cuestionamiento de las teorías predominantes sobre la formación del Estado inca.

KeYwords: Paisaje, Sistema de Información Geográfica, Inka, Periodo Intermedio Tardío, Cusco. 


\section{INTRODUCCIÓN}

Este artículo presenta datos arqueológicos recientes, procedentes de la prospección arqueológica realizada en el área de Ollantaytambo (Cusco, Perú), para examinar cómo fue que los grupos sociales de la región cuzqueña fueron incorporadas al Estado inka. En él se investiga cómo fue que deseando declarar su autoridad, los inkas transformaron el paisaje del Cusco, embelleciendo en particular la arquitectura de lugares preexistentes para la práctica ceremonial y regulando eventos rituales tradicionales. Al concentrarse en el proceso dinámico de articulación entre los grupos sociales locales de la región del Cusco y los inkas, cuestionamos las teorías predominantes de la formación del Estado inkaiko, las cuales tienen como base una interpretación literal de crónicas españolas específicas (v.g. Sarmiento 1965 [1572]), y que a menudo asumen que el temprano Estado inkaiko se formó fundamentalmente a través de la conquista violenta y la coerción. En general, este artículo contribuye a nuestra comprensión de la formación de dicho Estado, concentrándose menos en cómo fue que éste expresó su poder a través de las conquistas militares y las construcciones monumentales, y más en cómo fue que los inkas afianzaron su autoridad adoptando a, y apropiándose de, lugares y prácticas sagrados preexistentes.

Los datos aquí presentados se derivan del Proyecto Arqueológico de la Subregión de Wat'a (PASW), un proyecto de prospección arqueológica, análisis de artefactos y excavación de tres años de duración, dirigido conjuntamente por el Dr. Steve Kosiba (Profesor de Arqueología, Universidad de Alabama) y Vicentina Galiano Blanco. Para examinar cómo fue que los inkas incorporaron el área de Ollantaytambo, el PASW documentó la distribución de sitios, su trazado, el uso de la tierra y la cultura material en los periodos Intermedio Tardío («PITa», ca. 1000-1350 d.C.) e Inka (ca. 1350-1532 d.C.). El estudio empleó enfoques regionales -una prospección arqueológica sistemática y el análisis de Sistemas de Información Geográfica (SIG)- para evaluar si y cómo fue que los inkas construyeron su Estado regional, transformando la organización de los asentamientos y la economía de las comunidades locales. La investigación también utilizó enfoques locales como mapeos detallados, el análisis intensivo arquitectónico y de artefactos, y excavaciones extensivas para comprender cómo fue que los inkas declararon su autoridad, convirtiendo los espacios y edificios de poderosos centros políticos y santuarios locales. Este proyecto es el primer estudio sistemático de sitios arqueológicos, tipos de tierra y rasgos medioambientales de la región del Cusco que emplea los SIG, y la primera investigación arqueológica de la formación del Estado inka que integró la excavación y la prospección regional dentro de un solo programa de investigación. Los resultados del PASW ofrecen así una comprensión holista sin precedentes, de cómo fue que dicho Estado se consolidó mediante la transformación de las tradiciones y prácticas culturales antecedentes.

\section{¿UN IMPERIO NACIDO A SANGRE Y FUEGO? VISIONES CONTRASTANTES DE LA FOR- MACIÓN DEL ESTADO INKA}

Los inkas construyeron el imperio más grande de la América indígena, y sus mitos presentan una imagen uniforme de los dramáticos procesos de destrucción y subordinación, con los cuales inicialmente organizaron este extenso dominio. En estos mitos, ellos figuran como los divinos guardianes y cultivadores de un mundo caótico. Otros pueblos aparecen mayormente como bárbaros incivilizados, embrollados en guerras interminables: salvajes carentes de un liderazgo permanente, de leyes, pueblos y orden (Cieza 1971[1554]: 31, 33; Estete 1918[1535]: 330; Levillier 1940: 79; Pizarro 1965[1571]: 180; Polo de Ondegardo 1916[1571]: 117). A lo largo del siglo XVI, en particular, las elites inkaikas a menudo declararon a los españoles la tosca barbarie con la cual se toparon cuando originalmente expandieron las fronteras de su naciente Estado en el Cusco, y cómo, en conformidad con su divino mandato de gobernar, destruyeron las aldeas y santuarios de todo aquel que se considerara su igual, o cuestionara las pretensiones inkaikas de autoridad absoluta. En palabras de un temprano cronista español: 
«Era otro cinche llamado Illacumbi, cinche de dos pueblos, el uno nombrado Cugma y el otro Guata, cuatro leguas del Cusco. A este cinche enviaron a decir Inga Yupangui e Inga Roca que les viniese a dar obediencia, y respondióles que el era tan principal como ellos y libre, y que si algo querían, que lo habían de librar por las lanzas. Por esta respuesta tomaron las armas contra el dicho cinche. El cual y otros dos cinches sus compañeros, llamados el uno Paucar Topa y el otro Poma Lloqui, juntaron sus gentes y salieron a pelear con el Inga, mas fueron vencidos y muertos ellos y cuasi todos los del pueblo. Y asoló aquella población toda a fuego y a sangre con muy grandes crueldades. Y de allí se tornó al Cusco y triunfo de esta victoria» (Sarmiento 1965 [1572]: cap. 35).

En relaciones similares, los inkas cuentan como la población preinkaika de la región del Cusco era atrasada y bárbara, y que ellos por lo tanto forzaron a los demás grupos sociales a que se les unieran o fueran conquistados por su nuevo Estado (Fig. 1) (Levillier 1940; Sarmiento 1965[1572]; y véase Kosiba 2010, 2012). Parecería que la formación de su Estado conllevó una dramática ruptura social, a medida que una emergente clase de elite cuzqueña implantaba un nuevo orden regional en todas las regiones vecinas, $\mathrm{y}$ al hacerlo extinguió las tradiciones culturales y las pretensiones políticas de los pueblos locales.

Las tempranas teorías antropológicas de la formación del Estado inka propugnaban una interpretación literal de estas historias narrativas (véase Rowe 1944, 1946, 1985; Brundage 1963; Julien

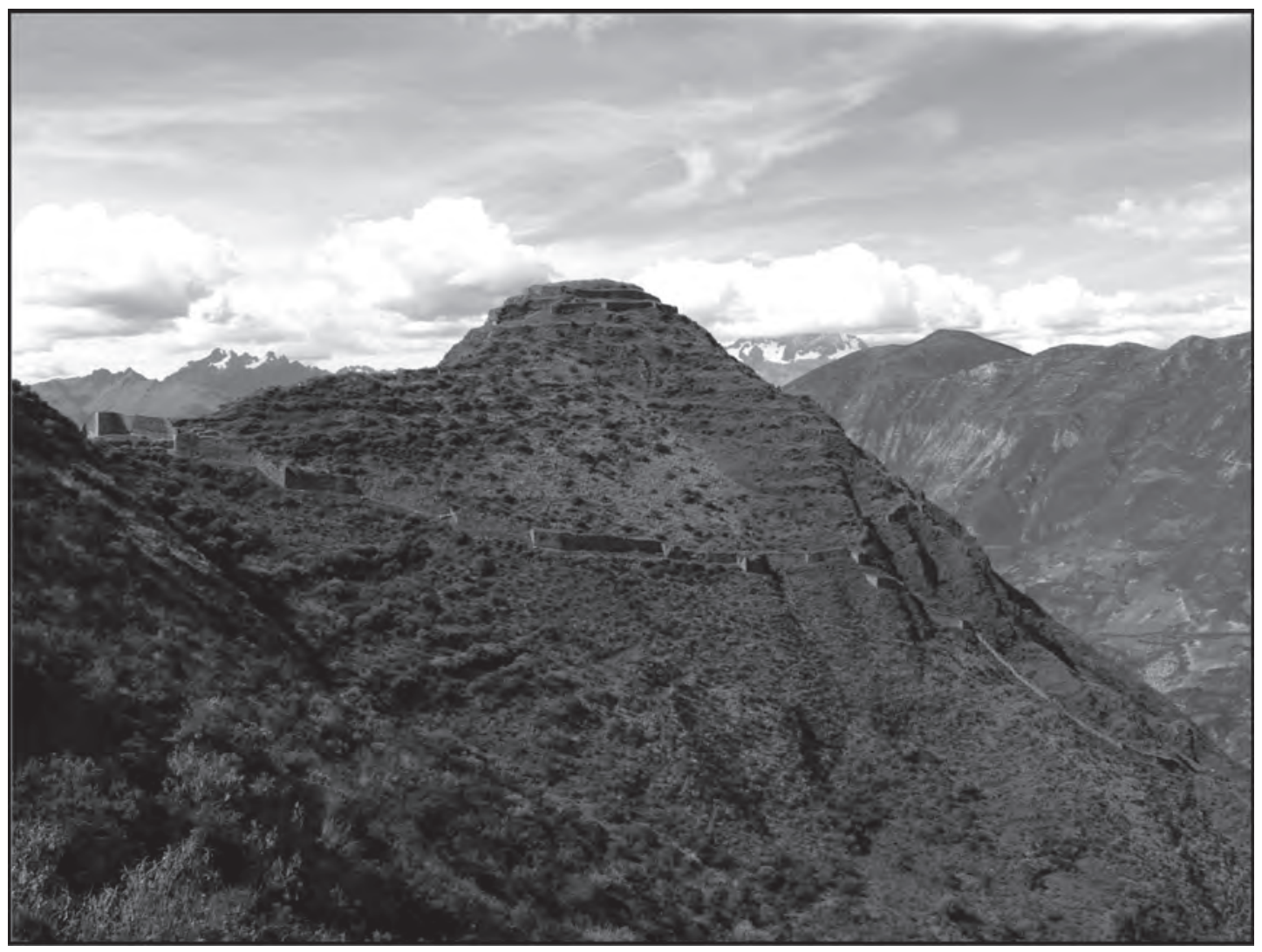

Figura 1. La crónica de Sarmiento de Gamboa describe cómo fue que los inkas conquistaron y destruyeron Wat'a, durante el proceso inicial de formación del Estado en el Cusco. Sin embargo, las recientes evidencias arqueológicas muestran que convirtieron este lugar en un centro ceremonial fortificado. 
2000; Niles 1987, 1999). ${ }^{1}$ El arqueólogo estadounidense John Rowe (1946), en particular, sostuvo que los inkas instituyeron su dominio sobre el Cusco alrededor de 1200 d.C., tras lo cual iniciaron, dos siglos más tarde, un programa de conquistas territoriales y de consolidación regional del Estado. ${ }^{2}$ Según la teoría de Rowe, fue Pachakuteq Inka Yupanki, el noveno emperador Inka, quien declaró su autoridad sobre áreas que caían fuera del Cusco, una vez que venció a los chankas, los viejos enemigos de su pueblo, en 1438 (Rowe 1946). Poco después, este gobernante estableció un Estado regional y dirigió la construcción de edificios monumentales, inventó las instituciones de gobierno, y desarrolló una ideología religiosa expansionista. En esta perspectiva, el Estado inka quedó consolidado gracias a los actos de un héroe cultural y un líder singular. Sin embargo, según dichas teorías, antes de Pachakuteq el Cusco no era más que un pequeño pueblo andino, y la región cuzqueña era un área bárbara de pequeñas jefaturas en guerra.

Pero no todos los investigadores aceptaron esta versión de la formación del Estado inka y la interpretación literal de las crónicas hispanas de la que depende (véase en particular Bauer 1992). Por ejemplo, la etnohistoriadora peruana María Rostoworowki de Diez Canseco (1978) sostuvo que el Estado inka surgió a partir de una red precedente de interacción interregional e intercambio socioeconómico. El arqueólogo Luis Lumbreras (1978) asimismo afirmó que cuando los inkas llegaron al poder, nuevos tipos de estatus social y de clase venían estableciéndose.

Sin embargo, durante décadas, estas hipótesis no fueron puestas a prueba y examinadas con las investigaciones arqueológicas. En el Cusco, la arqueología se concentró durante largo tiempo solo en el descubrimiento y la conservación de los sitios inkaikos más impresionantes y monumentales, como los palacios y templos que correspondían a la cúspide del dominio inka (Alcina Franch et al. 1976; Bengsston 1998; Burger y Salazar 2004; Dwyer 1971; Farrington y Zapata 2003; Gibaja Oviedo 1982, 1984; Nair 2003; Niles 1988, 1999; Paredes 2005; Protzen 1991, 2000; Valcárcel 1934, 1935; Valencia y Gibaja 1992). Dado que las investigaciones se concentraron en estos monumentos tardíos, las historias narrativas y las proposiciones que figuran en las crónicas españolas no fueron ni cuestionadas ni tampoco verificadas. Solamente unos cuantos asentamientos y centros ceremoniales ocupados durante la transición al dominio inka fueron excavados sistemáticamente (Dwyer 1971; Kendall 1984, 1996). En consecuencia, los arqueólogos solamente tenían una comprensión limitada de cómo fue que las instituciones y ceremonias gubernamentales inkaikas (como festejos ceremoniales en plazas, ritos funerarios y las prácticas de mita) reemplazaron o adoptaron a las tradiciones culturales previas, o cómo fue que los inkas incorporaron a distintos grupos étnicos mediante la conquista militar, las alianzas $\mathrm{u}$ otros procesos sociales.

Más recientemente, las prospecciones y excavaciones arqueológicas comenzaron a cuestionar las narrativas históricas referidas al surgimiento del Estado inka, y a demostrar que la integración política inkaika fue un proceso prolongado que se inició mucho antes de 1438, durante el Periodo Intermedio Tardío o Periodo Killk'e (Bauer 1992, 2004; Covey 2006; Kosiba 2010, 2012; McEwan 2006; McEwan et al. 2008). Las prospecciones arqueológicas sistemáticas revelaron las profundas raíces de la organización social preinkaika cerca del Cusco, al documentar cómo fue que los grupos étnicos establecieron formaciones políticas localizadas que tuvieron su centro en pueblos aglutinados que hacía largo tiempo estaban ocupados (Bauer 2004; Covey 2006; Kosiba 2010, 2012). Dicho estudios su-

1 Julio C. Tello (1937) fue uno de los primeros investigadores que cuestionó la veracidad y utilidad de las relaciones hispanas, y pidió que se llevaran a cabo investigaciones arqueológicas más extensas y focalizadas del surgimiento del Estado inka. Las investigaciones arqueológicas anteriores realizadas en el Cusco se concentraron en establecer categorías cronológicas a través de las cuales se podría comprender la historia inkaika (Pardo 1938, Uhle 1912; Valcárcel 1934, 1935). Las versiones históricas del Cusco temprano replicaron las historias de la conquista que encontramos dentro de las crónicas españolas (Prescott 1847).

2 Rowe extrajo estas conclusiones a partir de la crónica de Cabello de Balboa de 1586. 
gieren que los inkas tomaron el control de los recursos locales, y que trasladaron poblaciones cerca de las zonas de producción del maíz, en el piso del valle (Covey 2006; Heffernan 1989, 1996; Kendall 1984,1986,1988). Las excavaciones descubrieron contextos discretos del Periodo Intermedio Tardío (killk'e o lucre) debajo de los cimientos de las estructuras del Cusco inkaiko, lo cual sugiere que el Estado inka surgió después de una larga historia de desarrollos y cambios sociales (véase Cuba 2003, 2004; Kendall et al. 1992; McEwan 2006; McEwan et al. 2008). Es más, los estudios bioarqueológicos no encontraron evidencia alguna de conflictos generalizados en los siglos anteriores a, o durante, la formación del Estado inka: los esqueletos no muestran las típicas señales de trauma o violencia (Andrushko y Torres 2011).

Las recientes investigaciones ofrecen una nueva imagen de cómo fue que los inkas estructuraron su Estado temprano. Además, dichas investigaciones cuestionan la perspectiva «Cusco-céntrica» de las crónicas, las cuales sostienen que un pequeño grupo de parentesco del mismo pueblo de Cusco unificó la región circundante, y al hacerlo borró o reemplazó a las tradiciones culturales anteriores. De esta manera comenzamos a comprender el proceso de formación del Estado inka. Pero nuestros datos son limitados. Las prospecciones solamente proporcionan una vista panorámica y general de la economía política. Y las excavaciones sólo dan cuenta de cambios dentro de sitios específicos, y rara vez se comparan sus datos con los de otros sitios y regiones. Debemos primero comprender cómo se generaba la autoridad inkaika en los contextos locales de toda la región, para así poder poner a prueba las hipótesis sugeridas por Rostworowski (1978) y Lumbreras (1978), y mejorar además nuestros conocimientos de los lazos culturales regionales, las relaciones económicas y las alianzas políticas que deben haber precedido y contribuido a la formación del Estado inka. ¿Cómo podríamos definir las raíces culturales y sociales de dicho Estado dentro de la región del Cusco? En pocas palabras, ¿cómo podemos entender la perspectiva que las poblaciones locales tuvieron de la formación del Estado inka?

Tal vez sea útil reducir la escala de nuestra visión del Estado inka temprano -al cual a menudo se analiza sólo a escala regional- y concentrarnos en los lugares en donde originalmente se generó la autoridad inkaika (Kosiba 2012). Después de todo, los investigadores no toman en cuenta cómo, en las relaciones hispanas, los inkas explicaron repetidas veces que su incorporación de las nuevas áreas se concentró en centros ceremoniales, en los cuales derribaron viejos edificios y construyeron otros nuevos. Es más, los datos arqueológicos demuestran que durante los siglos que antecedieron a la supremacía inkaika, hubo lugares específicos (pueblos, fortalezas y santuarios) en las sierras de los Andes que acumularon un valor cosmológico y social para los grupos andinos (Arkush y Stanish 2005; D’Altroy 1992). Estos lugares eran una fuente poderosa de identidad social para los grupos de parentesco, y un componente esencial de su derecho a ser políticamente autónomos (Kosiba 2011). Queda claro que en todas las provincias del imperio, los inkas concentraron sus esfuerzos en la conversión de sitios específicos tales como el Templo de Wari Wilka (Cieza 1971[1554]: 311) o la isla del Sol en el lago Titicaca (Cobo 1990[1653]: 94), precisamente porque dichos sitios hacía tiempo eran reconocidos como fuentes de poder social.

Bajo esta luz, los inkas parecerían haber establecido su dominio mediante la captura y la conversión de lugares poderosos, centros políticos y santuarios. Entonces, para comprender las transformaciones sociales a través de las cuales se construyó el Estado inka, debemos averiguar los procesos a través de los cuales se reconstruyeron estos lugares y el paisaje que les rodeaba.

\section{LA ARQueOlogía dEL PAISAJE}

Para abordar estas cuestiones, debemos examinar cómo fue que la formación del Estado inka fue predicada sobre cambios en el paisaje social. En la teoría arqueológica, el término «paisaje» alude a las actividades y lugares sociales que organizan la experiencia que una persona tiene de su entorno social. Un paisaje es el marco cultural y político a través del cual se produce y percibe al medio ambiente, a distintas escalas, desde la casa en que uno vive, hasta la escala de su pueblo o región (Alcock 2002; 
Anschuetz et al. 2001; Ashmore y Knapp 1999; David y Thomas 2010; Smith 2003). Los arqueólogos que emplean el enfoque paisajístico enfatizan que los rasgos construidos y los recursos naturales del medio ambiente, no son simples condiciones a las cuales se adaptan las sociedades humanas, o escenarios sobre los cuales los seres humanos actúan. Ellos más bien se concentran en las actividades y practicas a través de los cuales la gente produce los sitios, santuarios y rasgos físicos de su medio ambiente, y la forma en que el entorno construido influye sobre los actos sociales de las personas (Smith 2003). En palabras de Little (1999: 263): «la[...] comprensión de los paisajes involucra el análisis de los sistemas de conocimiento, las actividades productivas y los ritos religiosos que los pueblos locales han desarrollado a lo largo de los siglos, como un medio a través del cual interactuar con, y ganarse el sustento de, sus medio ambientes biofísicos». Examinando los sitios arqueológicos, las actividades, materiales y variables medioambientales a través de Ollantaytambo, podemos conseguir un punto de ingreso analítico a los cambios sociales a través de los cuales se crearon originalmente el paisaje y el Estado inka.

\section{InVESTIGACIONES ANTERIORES EN EL ÁREA DE Ollantaytambo}

El PASW empleó esta perspectiva de los paisajes para comprender la historia social y medioambiental del área de Ollantaytambo. Ubicada aproximadamente a $30 \mathrm{~km}$ del centro del Cusco, su área de prospección quedó delimitada por la confluencia de tres profundos valles, el del Vilcanota, el cañón de Huarocondo y el valle de Patachancha (Fig. 2). La prospección se concentró en la organización social preinkaika e inka temprano dentro de esta área, antes de la construcción de Ollantaytambo.

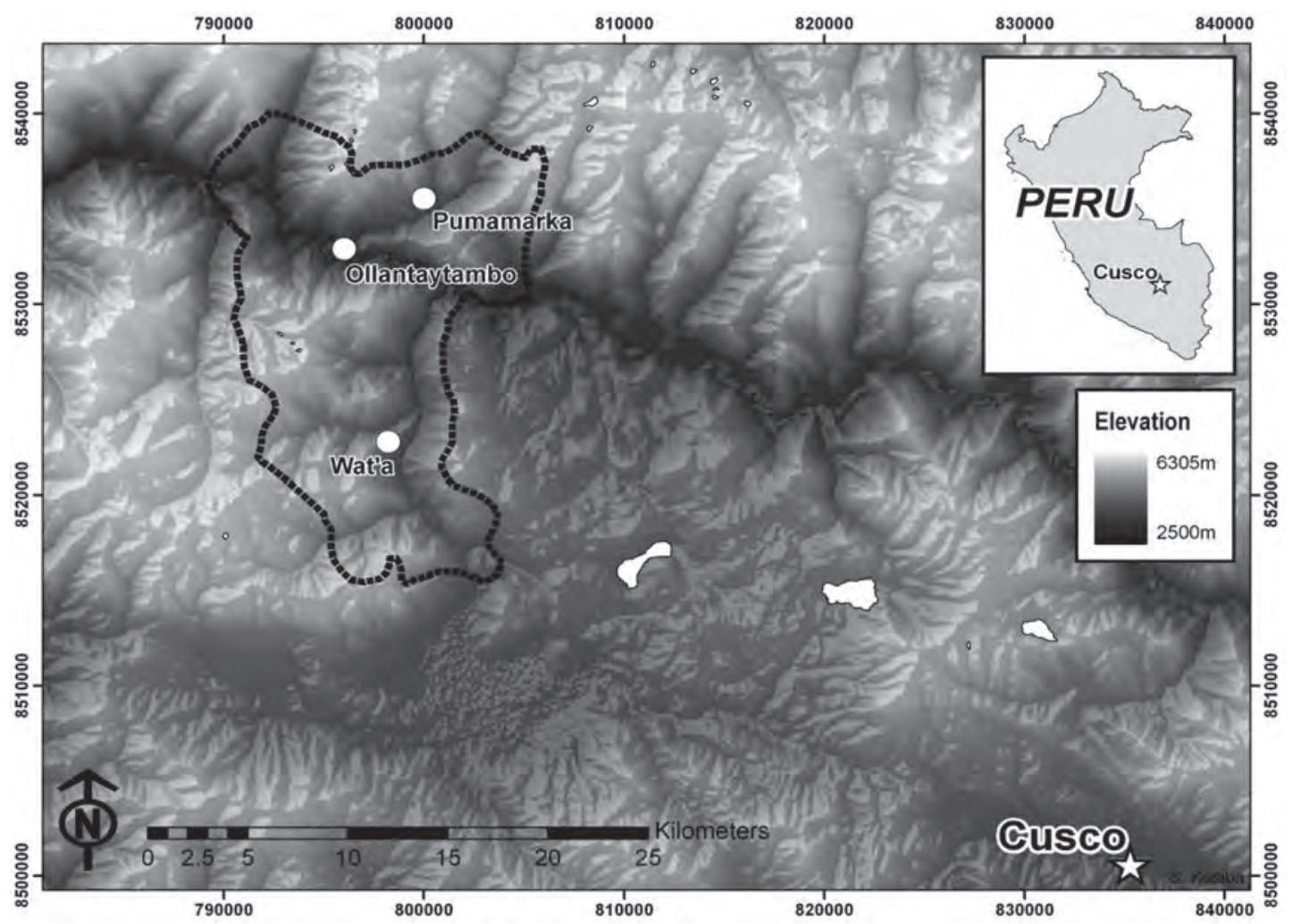

Figura 2. Este mapa muestra la ubicación de los sitios principales mencionados en el presente texto. La línea discontinua corresponde a los $200 \mathrm{~km}^{2}$ de la zona de prospección del Proyecto Arqueológico de la Subregión de Wat'a (PASW). 
La ciudad inka de Ollantaytambo fue construida durante el siglo XV y seguía bajo construcción al llegar los españoles (Protzen 1985, 1986, 1991; Rostworowski 1962; Rowe 1997; por fechados radiocarbónicas, veáse Bengtsson 1998; Hollowell 1987; Kendall 1985). Las fuentes etnohistóricas sugieren que sus macizos edificios y terrazas agrícolas geométricas fueron construidos durante el reinado de Pachakuteq (Protzen 1991; Rostworowski 1962; Rowe 1997). Las recientes excavaciones realizadas en Ollantaytambo respaldan esta postura, pues apenas revelaron evidencias limitadas de una ocupación preinkaika o inka temprano (Galiano y Marina 2004; Gibaja 1982, 1984; Kosiba 2010; Soto y Cabrera 1999; Vera 1986). En efecto, aunque se descubrió algo de cerámica temprana (killk'e) en las excavaciones, siempre se la encuentra en pequeña cantidad, en los mismos niveles que la cerámica inka clásico, y asociada con la arquitectura inka posterior. Estos factores indican que la cerámica killk'e, en este lugar, fue usada durante el periodo inka imperial, y no eran restos de un asentamiento preinka. En suma, es posible que haya habido una ocupación anterior en Ollantaytambo, pero para esclarecer su extensión y función necesitamos contar con más investigaciones. Actualmente lo único que queda claro es que la ciudad fue una instalación inka imperial.

Varios proyectos arqueológicos han identificado sitios preinkaikos significativos en el área de Ollantaytambo. El reconocimiento arqueológico en las cercanías de Cusichaca y Limatambo ubicó numerosos asentamientos preinkaikos, y documentó la construcción de sitios monumentales inkas cerca del piso del valle (Heffernan 1988; Kendall 1984, 1986, 1996; Lunt 1987). Se ha excavado en los sitios preinkaikos de Wat'a y Pumamarka, así como en los sitios vecinos de la cuenca de Cusichaca. Las excavaciones y los fechados radiocarbónicos asociados, indican que estos sitios estuvieron ocupados durante siglos antes del periodo inka, sugiriendo así que unos poderosos grupos sociales preinkaikos poblaron esta zona (Cuba 2003, 2004; Kendall 1992, 1996; Kosiba 2010, 2012). Usando estos datos como punto de partida, el PASW llevó a cabo una prospección sistemática de todos los sitios arqueológicos y un análisis medioambiental de todas las tierras agrícolas, para evaluar plenamente cómo fue que los inkas convirtieron esta zona en una parte principal de su centro cuzqueño.

Las fuentes históricas asimismo arrojaron cierta luz sobre el paisaje preinkaiko de Ollantaytambo, sugiriendo así que unos poderosos grupos étnicos locales vivieron en la zona antes del surgimiento de los inkas. Por ejemplo, el grupo étnico quilliscache residía en el área meridional de la zona de la prospección, cerca del actual pueblo de Huarocondo, en tanto que los tampu estuvieron en la parte norte de dicha zona, cerca de Ollantaytambo. Estos grupos fueron incorporados durante el proceso inicial de formación del Estado inka, y posteriormente continuaron siendo miembros integrales de la jerarquía imperial del área del Cusco, se convirtieron en «inkas de privilegio» y fueron aliados leales de la facción cuzqueña (Waskhar) durante la guerra civil inkaika (según Garcilaso de la Vega 1965[1609]: 5657; Guaman Poma 1980[1615]: 310; Santa Cruz Pachakuti Yamqui 1968[1613]; Sarmiento 1965[1572]). El PASW nos da una perspectiva íntima de las transformaciones sociales que tuvieron lugar, a medida que estos dos grupos étnicos del Cusco fueron reconfigurados y asumieron papeles importantes en el centro imperial inkaiko.

Dados los resultados de la investigación arqueológica e histórica, esperábamos encontrar evidencias de una ocupación preinkaika de larga duración en la región de Ollantaytambo. Pero también esperábamos encontrar que los inkas cambiaron drásticamente el paisaje social. Considerando la información histórica, esperábamos que los patrones de asentamiento y estilos materiales preinkaikos de la región de Ollantaytambo estuvieran concentrados en dos áreas separadas, reflejando así la existencia y las pretensiones territoriales de dos grupos étnicos distintos. 


\section{MÉTODOS: PROSPECCIÓN ARQUEOLÓGICA Y ANÁLISIS SIG}

Combinando una prospección arqueológica intensiva de cobertura total con Sistemas de Información Geográfica (SIG) y el análisis de artefactos, el PASW documentó: (1) los tipos de tierra, para comprender las actividades agrícolas y la economía, (2) la ubicación de los sitios arqueológicos, para comprender la organización de los asentamientos, los tipos de sitios y los lugares ceremoniales, y (3) los artefactos al nivel de la superficie, para comprender las actividades y los materiales ceremoniales.

En primer lugar, para examinar la relación existente entre la ubicación de los sitios arqueológicos y los recursos agrícolas en los periodos preinka e inka, el proyecto analizó los tipos de tierra. Kosiba identificó los terrenos idóneos para la producción del maíz gracias a un análisis SIG intensivo de la pendiente y la altura, el examen de la reflectancia del suelo usando imágenes de satélite, y detalladas observaciones de campo de la condición del suelo, la erosión, la geología y la agricultura actuales. El terreno de producción del maíz (TPM) fue definido como la tierra que cumple con los requisitos biológicos de esta planta sin necesidad de terrazas o riego (Gade 1975; Hastorf 1993). Más específicamente: (1) las tierras ideales de producción del maíz tendrán una pendiente de menos de diez por ciento y estarán a una altura de menos de 3200 m (TPM1), y (2) el terreno suficiente para la producción de maíz tendrá una pendiente de menos de quince por ciento y estará ubicado a una altura de menos de 3500 m (TPM2).

En segundo lugar, el proyecto documentó sitios arqueológicos, rasgos arquitectónicos y estilos alfareros por toda la región. Los arqueólogos caminaban siguiendo líneas paralelas separadas 30-50 $\mathrm{m}$ la una de la otra. En todos los sitios se tomaron puntos de Sistemas de Posicionamiento Global (GPS). Se tomaron las medidas de la arquitectura (Kosiba y Bauer 2012). En cada sitio se recogió una muestra de artefactos de superficie. Kosiba posteriormente volvió a los sitios que tenían más de una hectárea para efectuar colecciones sistemáticas; las unidades de recolección fueron distribuidas a lo largo de los sitios usando una estrategia de muestreo sistemático estratificado no alineado (véase Kosiba 2010).

En tercer lugar, el proyecto analizó la distribución de los tipos cerámicos y los estilos arquitectónicos correspondientes a actividades ceremoniales, como fiestas. La importancia que estos eventos tienen en la política y la vida social andinas está bien documentada (Bray 2003; Costin y Earle 1989; Cummins 2002; D’Altroy y Hastorf 2001; Hastorf 2001, 2003; Jennings 2004; Morris y Thompson 1985; Ogburn 2005; Ramírez 2005). El PASW estudió los tipos arquitectónicos (plazas, sectores mortuorios, plataformas aterrazadas, grandes edificios) asociados con el ceremonialismo en el PITa y el periodo inka. La prospección documentó las densidades y porcentajes de artefactos a nivel de la superficie, en particular las vasijas de servicio decoradas, en relación a la muestra total de artefactos recuperados. Estas vasijas y otras formas alfareras fueron clasificadas mediante la categorización de los tipos de bordes de más de 8,000 tiestos excavados, provenientes de la prospección (véase Kosiba 2010).

Los estilos alfareros preinkaikos fueron clasificados según las tipologías establecidas en el Cusco. Las significativas regularidades estilísticas presentes en la cerámica preinkaika nos hicieron definir un nuevo tipo alfarero. Dicho tipo se encuentra caracterizado por la correspondencia de motivos decorativos, estilos de manufactura y tipos de borde en la cerámica derivada de los niveles estratigráficos preinkaikos de Wat'a, que arrojaron fechados radiocarbónicos de mediados del siglo xiII y del siglo XIV (Kosiba 2010). Como dichos estilos parecen ser particulares de la región de Ollantaytambo, llamamos a esta cerámica el tipo «Fase Ollantaytambo» o «Fase Ollanta.» Hay cinco variaciones diagnósticas de este tipo por toda el área de la prospección, entre ellos: ollanta negro sobre rojo, ollanta rojo, ollanta negro sobre blanco, ollanta rojo sobre blanco y ollanta sencillo (Fig. 3). Hay versiones de los mismos motivos decorativos de línea gruesa y fina. Los colores de la pasta son anaranjado oscuro o rojo. Las inclusiones cerámicas son de tamaño irregular y forma angular, y frecuentemente incluyen arena, así como grandes trozos de feldespato, cuarcita y arcilla cocida (grog). 


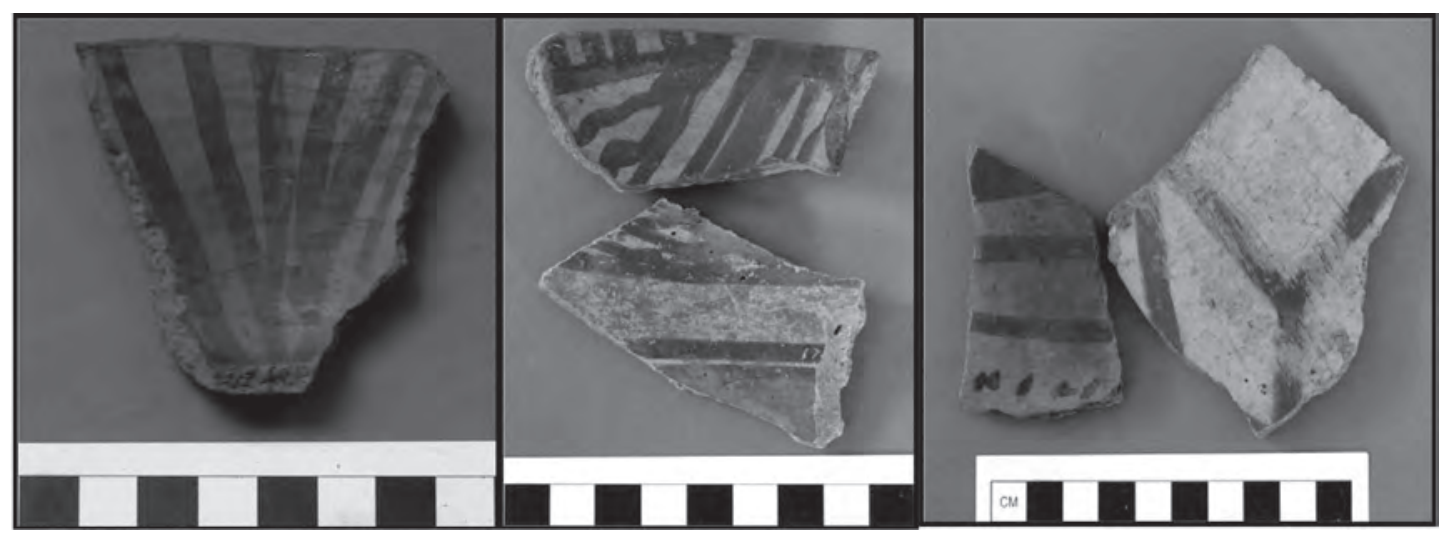

Figura 3. Algunas vasijas de servicio decoradas (tazones), representativas de la FO. Adviértase que los tazones tienen los lados rectos y que a menudo están decorados con líneas gruesas. Aquí están retratados ollanta negro sobre sencillo (derecha), negro sobre rojo (centro) y negro y rojo sobre ante (izquierda).

Los estilos alfareros de la Fase Ollanta comparten motivos decorativos con el ampliamente distribuido estilo killk'e, que en la región del Cusco se encuentra típicamente asociado con el Periodo Intermedio Tardío (Alcina Franch et al. 1976; Bauer 1999; Haquehua Huaman y Maqque Azorsa 1996; Kendall 1976, 1985, 1996; Lunt 1984, 1987; Rowe 1944). ${ }^{3}$ Los motivos decorativos killk'es frecuentemente se encuentran sobre tipos de vasijas de servicio (en particular, los tazones de lados rectos), en contextos arqueológicos de la región cusqueña que datan de entre los siglos XI y XVI (Bauer 1992, 2002, 2004; Bauer and Covey 2002; Chatfield 2007, 2010; Covey 2006, 2008; Kosiba 2010). Sin embargo, los atributos específicos de la cerámica de la Fase Ollanta -recetas distintas para la pasta, los colores de la arcilla, los tipos de inclusiones y las formas de los bordes- muestran un proceso distinto de manufactura que la cerámica killk'e de otras áreas cercanas al Cusco. Es más, la cerámica de la Fase Ollanta a menudo está pintada con líneas más gruesas y brochazos más anchos que otros tipos killk'es. Estos atributos indican que la cerámica de esta fase son variantes distintas y de manufactura local, de un estilo decorativo que estuvo ampliamente distribuido entre los grupos sociales de la región del Cusco durante el Periodo Intermedio Tardío.

Usamos por ello el término «Fase Ollanta» (FO), cuando nos referimos a los materiales y sitios que precedieron directamente al dominio inka dentro del área de Ollantaytambo (ca. 1000-1300 d.C.). Este término local brinda más precisión al documentar las variaciones en los motivos decorativos y los atributos tecnológicos de la cerámica. «Inka Temprano» alude al periodo de transición al dominio inkaiko, un periodo en el cual las formas arquitectónicas y los estilos materiales inkas aparece por vez primera en los sitios locales (ca. 1300-1400 d.C.). Este periodo es visible en las formas arquitectónicas: edificios con elementos estilísticos del canon arquitectónico inka (v.g. portadas de doble jamba, nichos, paredes de 80-100 cm de grosor, forma cuadrangular), pero que también retienen rasgos arquitectónicos más tempranos (esquinas internas redondeadas, piedras de campo a las que no se ha dado

3 El mismo término «killk'e» resulta problemático. Los investigadores a menudo asumen que este estilo decorativo fue producido en el valle del Cusco antes del Estado inka (Bauer 1992, 2002, 2004; Bauer y Covey 2002; Covey 2006, 2008; cf. Chatfield 2007, 2010). Sin embargo, todavía no se efectúa ningún estudio de la composición cerámica elemental, ni se ha encontrado un centro de producción. Por ende, cuando aludimos a los siglos XI y XIV en la región del Cusco, resulta más exacto (1) usar el término «killk'e» para aludir a motivos decorativos comunes encontrados en las vasijas de servicio; y (2) distinguir tipos alfareros locales a fin de documentar la cronología de la cerámica y las formas de vasijas de grupos sociales particulares. 
forma). Tales edificios no muestran los rasgos estilísticos y de manufactura de estructuras imperiales posteriores (v.g. los techos de dos aguas, las esquinas internas en ángulo recto, formas rectangulares, piedras talladas) (véase Kosiba y Bauer 2013). El cuadro 1 muestra las cronologías regionales establecidas para las provincias inkaikas (Ica) (Rowe 1967) y el Cusco (Rowe 1944, 1945, 1946; Bauer 1992, 2004; Covey 2006; McEwan et al. 2008).

\begin{tabular}{|c|c|c|}
\hline Región del Cusco & Provincias inkas (Ica) & Fechas \\
\hline $\begin{array}{c}\text { Fase Ollanta (Ollantaytambo) } \\
\text { o Periodo Killk'e (Cusco) }\end{array}$ & Periodo Intermedio Tardío & ca. 1000 - 1300 d.c. \\
\hline Periodo Inka Temprano & Periodo Intermedio Tardío & ca. 1300 - 1400 d.c. \\
\hline Periodo Inka Imperial & Periodo Inka Imperial & ca. $1400-1533$ d.c. \\
\hline
\end{tabular}

\section{Cuadro 1: La cronología de la región del Cusco}

Usando estas categorías, la prospección rastreó la distribución de vasijas de servicio decoradas específicas en relación con otras formas cerámicas y densidades de artefactos, estilos morfológicos arquitectónicos, categorías de tierras y tipos de asentamiento. De este modo, el proyecto documentó cambios en los sitios y en los espacios ceremoniales en el área de Ollantaytambo, a lo largo de toda la Fase Ollanta y durante el primer siglo de dominio inka.

\section{El ÁRea de Ollantaytambo antes del dominio InKa}

La prospección documentó ochenta y dos sitios con evidencia de ocupación en la FO (Fig. 4). Los sitios estaban dispuestos en cuatro densas concentraciones. Solamente dos de las cuatro concentraciones de asentamientos se encuentran en las áreas mencionadas en las crónicas, lo cual sugiere que más de dos grupos étnicos vivieron en esta zona antes del surgimiento de los inkas. Aunque no hay un solo sitio que domine toda la región en términos de su tamaño o complejidad arquitectónica, sí se distinguieron sitios escogidos (Huamanmarka [W-027], Wat'a [W-041], Sulkan [W-043], Llactallactayoq [W-144], Huaylluhuaylloq [W-149], Pumamarka [W-124], Markaqocha [W-168] y Yanawara [W-176]) de los sitios circundantes, no necesariamente por su tamaño pero sí por otras variables, especialmente la elaborada arquitectura doméstica, los complejos mortuorios y las plataformas o plazas (Kosiba 2010). En la superficie de todos estos sitios había una alta densidad de artefactos. Uso el término «pueblo» al referirme a ellos, a fin de enfatizar que eran centros políticamente significativos de actividad ceremonial, en particular tal como lo evidencia la presencia de vasijas de servicio decoradas, estilos arquitectónicos especiales y complejos mortuorios.

¿Cómo explicamos la organización de este paisaje preinkaiko? Para comprender los siglos anteriores al dominio inka y su influencia sobre el desarrollo del Estado inkaiko, necesitamos dilucidar aún más las actividades socioeconómicas y ceremoniales que definieron a estas concentraciones de asentamientos, así como las actividades y materiales que a lo largo del tiempo, diferenciaron a los poblados de otros sitios vecinos.

\section{El desarrollo de los asentamientos preinkaikos y el uso de la tierra en el área de ollantaytambo}

Las cuatro concentraciones de asentamientos reflejan continuidades de larga duración en el uso de la tierra y la organización social. Los datos de nuestra prospección indican que estos patrones se mantuvieron más o menos a lo largo de milenios, desde el Periodo Formativo (ca. 2000 a.C. - 200 a.C.), pasando por el Periodo Intermedio Temprano (ca. 200 a.C. - 600 d.C.) y el Horizonte Medio (ca. 600 d.C. - 1000 d.C.) a la Fase Ollanta (Fig. 5). Los sitios del Periodo Formativo en el área de la prospección estaban ubicados en las mismas áreas que las concentraciones de asentamientos de la Fase Ollanta. Significativamente, no hay ninguna evidencia de cambios en la organización de los asentamientos durante el Horizonte Medio, cuando el Estado wari ejerció su influenza y control en las regiones veci- 


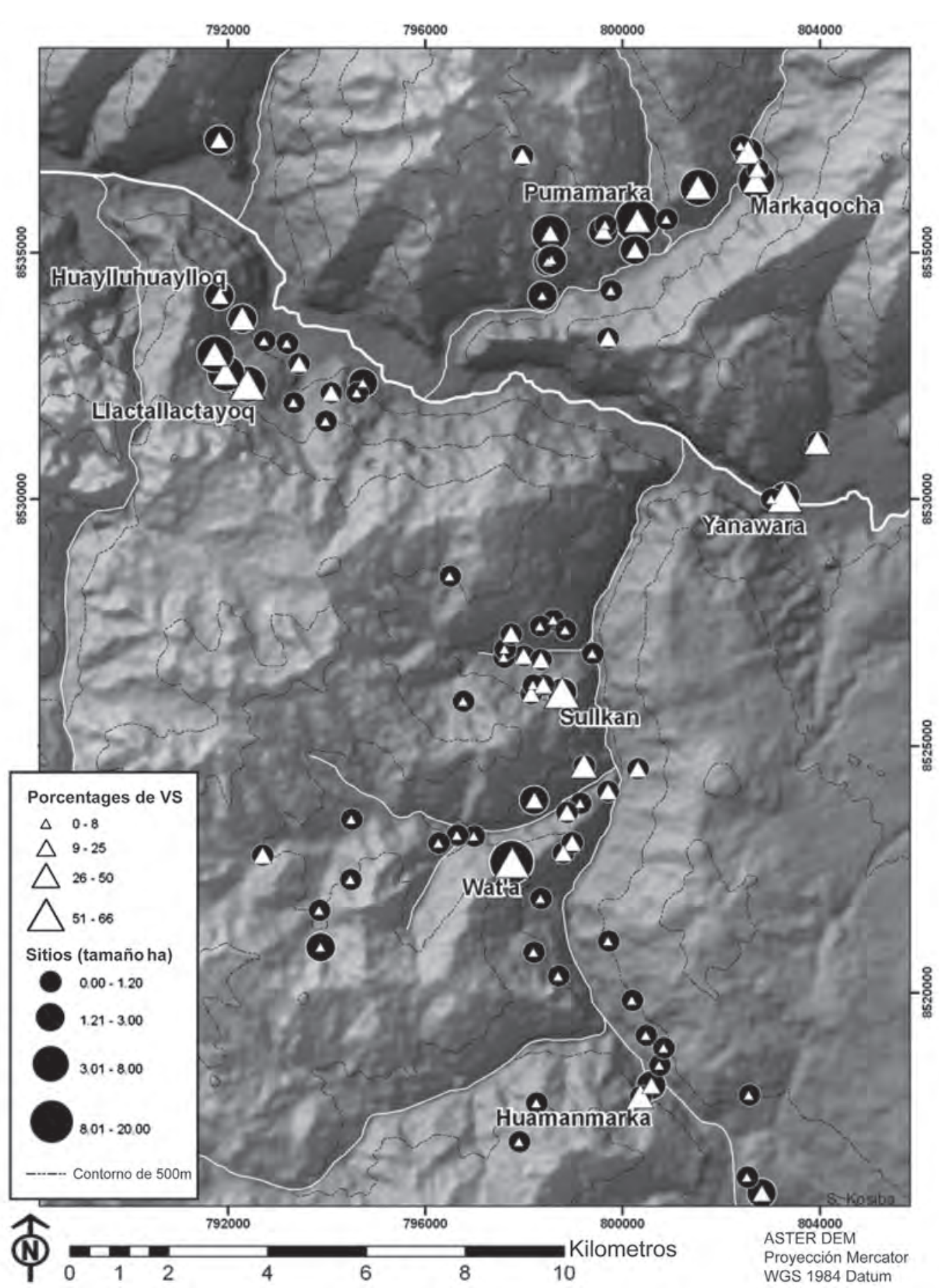

Figura 4. Este mapa muestra los asentamientos de la FO (círculos) y los porcentajes de las vasijas de servicio (VS) (triángulos) documentados en la zona de la prospección. El mapa muestra un patrón de asentamientos concentrado. También muestra que los altos porcentajes (>25\%) de vasijas de servicio decoradas están asociados únicamente con sitios específicos (los poblados). 


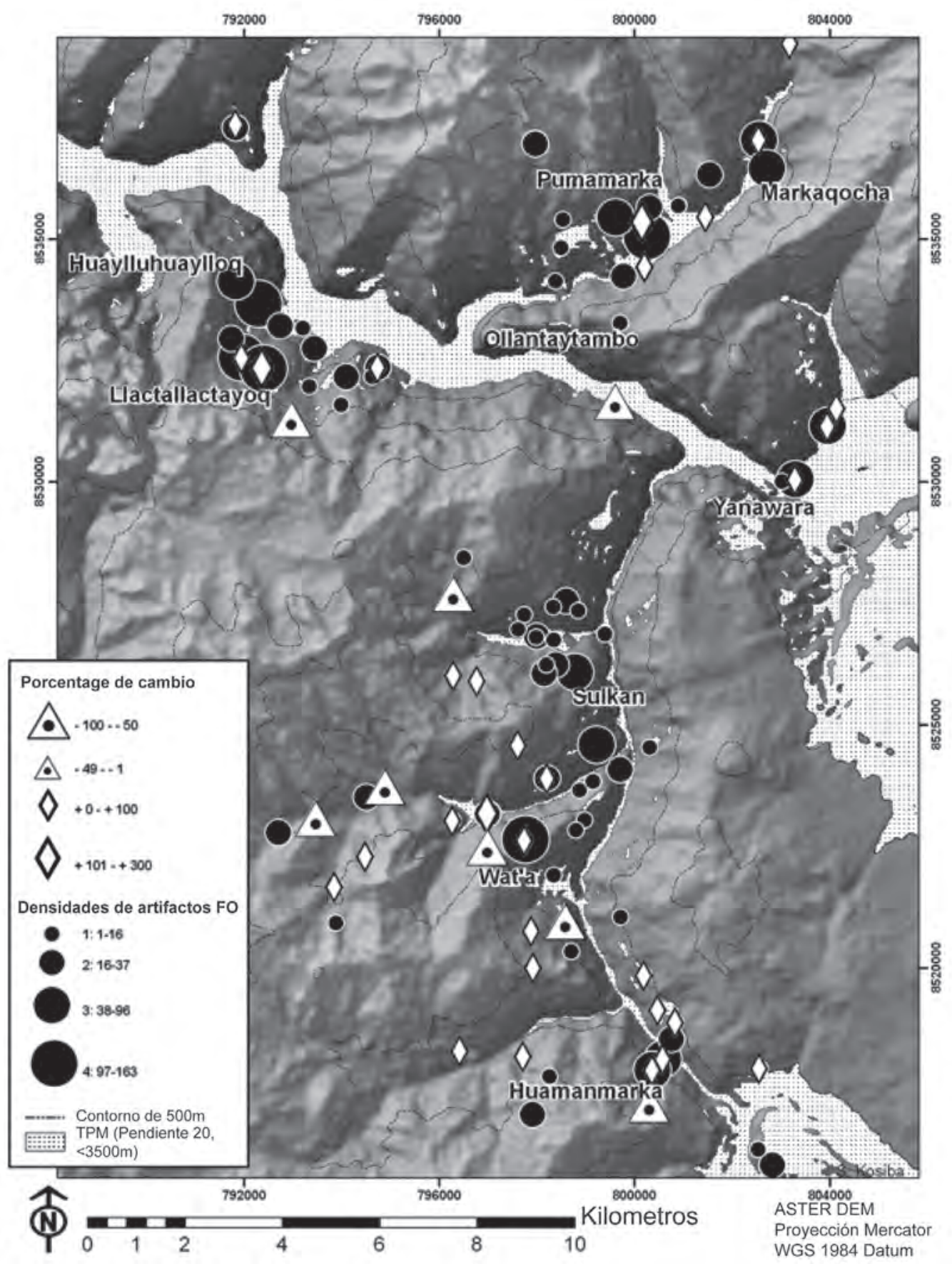

Figura 5. Este mapa muestra la historia de la ocupación, desde el Periodo Formativo hasta la Fase Ollanta. Los índices de cambio porcentual sugieren fluctuaciones en la historia de la ocupación. Un índice negativo (triángulo blanco) refleja la disminución en los materiales del nivel de la superficie de un periodo al otro, en tanto que uno positivo (un rombo blanco) refleja un incremento. Los índices de cambio porcentual demuestran que tierras, microrregiones y valles específicas estuvieron ocupadas continuamente durante miles de años. 
nas. Dicho Estado construyó un masivo complejo urbano en Pikillacta, en el valle del Cusco, y un sitio administrativo en Vilcabamba, más allá de Ollantaytambo (Bauer 2004; McEwan 1991, 1996, 2005). A pesar de la inversión wari en estas áreas, nuestra prospección no documentó los estilos arquitectónicos o los materiales estándares que significan la administración wari. Específicamente, aunque la prospección documentó treinta y dos sitios ocupados durante todo el periodo de la expansión estatal wari, su cerámica solamente fue recuperada en dos de ellos. La ausencia relativa de tales estructuras y materiales waris en la prospección sugiere vigorosamente que la zona de Ollantaytambo estuvo fuera del área de control directo de Wari (Kosiba 2010).

Los patrones de asentamiento en el área de Ollantaytambo se mantuvieron estables durante y después del colapso wari, lo que sugiere que las formas de vida local en dicha área se mantuvieron, no obstante los cambios políticos y económicos regionales. La mayoría de los sitios (74\%) del Periodo Formativo, Qotakalli (Periodo Intermedio Temprano) y Horizonte Medio continuaron ocupados durante la FO. En ellos, las densidades de la cerámica de superficie son consistentes del Formativo a la FO, lo que sugiere que el sitio y su intensidad de ocupación se mantuvieron. Solamente dos sitios -Anapawa y K'anaqchimpa-fueron parcialmente abandonados o despoblados al finalizar el Horizonte medio.

Múltiples análisis SIG examinaron si la ubicación de los asentamientos cambió con respecto a las prácticas de uso de la tierra. Los arqueólogos han señalado que a lo largo y ancho de los Andes, el final del Horizonte Medio a menudo coincide con un giro general en su uso. Ellos plantean la hipótesis de que unos cambios ecológicos bien documentados (una sequía prolongada), hicieron que muchas poblaciones locales abandonaran los asentamientos a más baja altura y construyeran pueblos cerca de fuentes de agua, encima de las cumbres de cerros y montañas (D’Altroy 1994). Sin embargo, nuestros análisis no encontraron un cambio en la ubicación altitudinal de los sitios, o movimiento significativo alguno de alejamiento de los posibles maizales (Fig. 6). La mayoría de los sitios (71,4\%), en particular, se mantuvo en áreas que están a una caminata relativamente breve ( $500 \mathrm{~m})$ de los maizales. Además, la mayoría de los sitios (66\%) recién establecidos de la FO estaban ubicados en o cerca de ellos. Estos patrones de ubicación son evidentes tanto dentro de la parte norte como la parte sur del área de la prospección, no obstante las diferencias en el área global del terreno potencial de maíz de los valles de la región. Así, los datos sugieren el mantenimiento y el uso continuo de maizales y pastizales.

Considerados en conjunto, los datos del uso de la tierra y de la prospección sugieren vigorosamente que estas concentraciones de asentamientos eran una forma de organización establecida hacía largo tiempo, que ligaba a grupos sociales con tierras específicas. Estos datos contrastan y complementan los resultados de prospecciones sistemáticas realizadas en otras partes de la región del Cusco. Covey (2006) revela que en el área al noreste del Cusco se produjeron drásticos cambios en el patrón de asentamientos al inicio del Periodo Intermedio Tardío, a medida que las poblaciones abandonaban el piso del valle en busca de terrenos más altos. Bauer (2004), sin embargo, documentó una continuidad en las ocupaciones en el valle del Cusco, similar a los patrones documentados en el área de Ollantaytambo. En suma, no existe un único patrón de cambio que caracterice a toda la región del Cusco, como sería de esperar si todos los grupos locales hubiesen estado sujetos a una convulsión política, económica o ecológica uniforme. Los datos comparativos sugieren que las diferencias locales en la organización socioeconómica, el contexto histórico, o tal vez incluso en las alianzas políticas, influyeron sobre el desarrollo de distintos patrones de asentamiento preinkaikos en toda la región del Cusco. En suma, los pueblos preinkaikos eligieron vivir localmente y organizar sociedades locales. Ellos no reaccionaron simplemente a cambios políticos o ecológicos más amplios, sino que más bien desarrollaron formas de organización social firmemente arraigadas en los suelos locales.

En realidad, el patrón de asentamientos de la FO muy probablemente se vio influido por la necesidad percibida de una mayor cercanía de los asentamientos, ligada tal vez a la preocupación con la seguridad agrícola o la autonomía social, en una época de cambio ecológico y político-económico (véase Wernke 2003, 2006a, 2006b, 2013). Las microrregiones separadas que estos grupos poblaban contaban con tierras tanto de pastoreo como para maizales, lo que sugiere que dichos grupos se dedicaban a ru- 


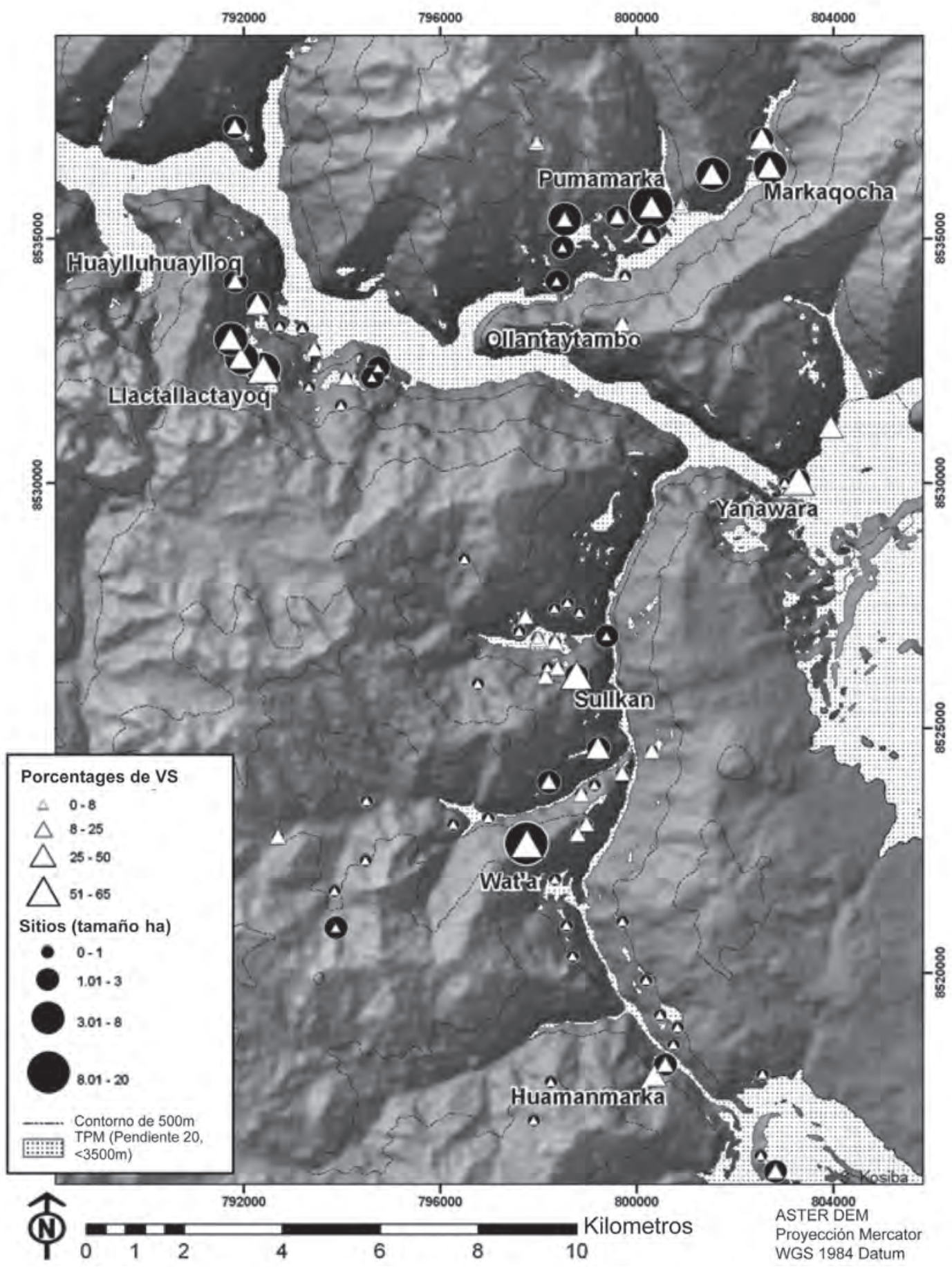

Figura 6. Los asentamientos de la FO y la densidad de las vasijas de servicio, en relación con el terreno potencial de producción de maíz. 
tinas económicas agropastorales altamente localizadas y complementarias. Estas concentraciones de asentamientos probablemente estuvieron organizadas como economías verticales compactas: áreas de actividades agrícolas y pastorales localizadas, en donde la población explotaba estratégicamente zonas ecológicas adyacentes (Brush 1976; Hastorf 1993: 185-186; Yamamoto 1985). Una economía local como ésta habría respaldado las pretensiones de estos grupos a la autosuficiencia y la autonomía sociales. Una mayor investigación de estas concentraciones de asentamientos revela la organización de la vida social y política en toda la zona, lo que nos permite poner a prueba las teorías (Lumbreras 1978; Rostworowski 1978) acerca de las condiciones culturales y económicas locales que precedieron al desarrollo del Estado inka en toda la región del Cusco, e influyeron sobre él.

\section{La organización social y política de la Fase Ollanta}

A partir de estos resultados se efectuaron análisis para examinar cómo fue que se coordinaron las actividades ceremoniales y económicas durante la Fase Ollanta. En primer lugar, el análisis de la distribución de los estilos alfareros midió si la producción de cerámica estuvo organizada localmente. Esto nos dio una percepción preliminar con la cual evaluar la hipótesis de Rostworowski (1978) acerca del intercambio socioeconómico y cultural, además de datos que complementan las recientes prospecciones arqueológicas de los grupos étnicos preinkaikos de la región del Cusco (Bauer 2004; Covey 2006). En segundo lugar, el examen de los atributos arquitectónicos y las densidades de artefactos de los sitios, evaluó cómo fue que las rutinas agropastorales fueron coordinadas dentro de las concentraciones de asentamientos. En tercer lugar, el examen de los sitios dentro de cada concentración sugiere cómo fue que ellas estuvieron estructuradas políticamente, lo que nos ofrece datos con los cuales evaluar las observaciones que Lumbreras (1978) hiciera de la dinámica de clases durante la formación del Estado inka.

Un análisis intensivo de los tiestos recogidos en la superficie de sitios en cada concentración de asentamientos, identificó tanto similitudes regionales como diferencias locales en las técnicas de manufactura y decoración de la cerámica. El análisis consideró las cuatro concentraciones de asentamientos reveladas por la prospección, que fueron clasificados del siguiente modo: «Wat'a» (al sur, en el cañón de Huarocondo), «Kachiqhata» (al noroeste, en el cañón del mismo nombre), «Pumamarka» (al norte, en el valle de Patacancha), y «Yanawara» (al noreste, en la planicie del mismo nombre). Aunque todos los sitios dentro de la región de la prospección tienen en general cerámica con tipos y motivos decorativos de la FO, el análisis midió si había atributos que definían la alfarería hallada dentro de cada concentración de asentamientos. La distribución local de atributos específicos sugiere la producción local de cerámica, en tanto que la distribución regional de atributos particulares podría sugerir estilos culturales compartidos o intercambios. El análisis consideró una muestra de 746 vasijas decoradas que no eran de servicio, y 565 que sí lo eran.

En conjunto, los datos sugieren que la producción alfarera estuvo organizada localmente dentro de cada concentración de asentamientos, pero la cerámica ceremonial y las vasijas de servicio estaban decoradas de modo similar. ${ }^{4}$ Los análisis no encontraron diferencias significativas en las técnicas de manufactura (preparación y tipos de inclusión, oxidación), el color de la pasta, las formas de los bordes o la decoración. Estas similitudes sugieren cierto grado de conocimiento técnico compartido entre las personas que produjeron dichos estilos alfareros. Es más, en las vasijas de servicio se observaron motivos de diseño y un tratamiento de las superficies externas, que son comunes entre las

4 En particular, los análisis de chi-cuadrado pusieron a prueba las diferencias, por concentración de asentamientos, en los tiestos decorados de las vasijas que no son de servicio, y las diferencias en los tiestos de las vasijas que sí son de servicio. Todas las diferencias fueron significativas al nivel alfa de 0,01 . Diferencias en el engobe entre tiestos decorados de vasijas que no son de servicio: $X^{2}=1,363 ; \mathrm{df}=$ 3. Diferencias en el pulido entre tiestos decorados de vasijas que no son de servicio: $X^{2}=83,228 ; \mathrm{df}=3$. Diferencias en el engobe entre tiestos decorados de vasijas de servicio: $X^{2}=1.303 ; \mathrm{df}=3$. Diferencias en el pulido entre tiestos decorados de vasijas de servicio: $X^{2}=59,608 ; \mathrm{df}=3$. 

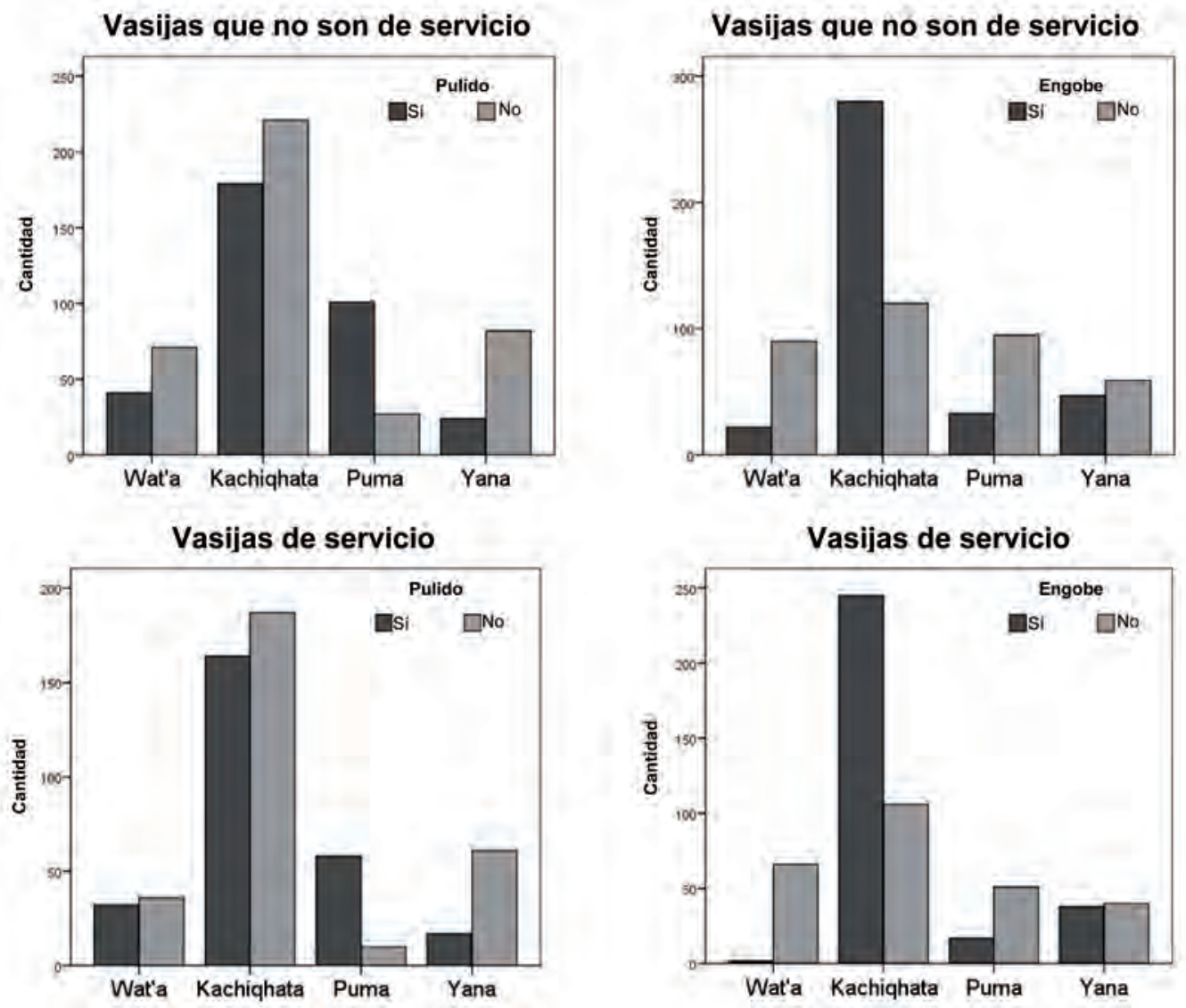

Figura 7. Producción local de cerámica durante la FO. Estos gráficos ilustran los patrones en los atributos decorativos de la cerámica, tal como aparecen en las cuatro concentraciones de asentamientos presentes en la zona en donde se llevó a cabo la prospección.

concentraciones de asentamientos. Específicamente, en la mayoría de las concentraciones, las vasijas de servicio estaban decoradas con la aplicación de un engobe de color crema claro, que cubría unas pastas de color naranja o rojo oscuro. Además, la superficie externa de muchos tiestos luce un fuerte patrón de pulido, que tiene el aspecto de surcos profundos grabados sobre la superficie de una olla. Estos hallazgos sugieren que para la población de cada concentración era importante usar, en sus actividades políticas y ceremoniales, una cerámica que portara motivos decorativos regionalmente reconocibles. Los datos sugieren así que no obstante la organización local de los asentamientos, los pueblos preinkaikos del área de Ollantaytambo desarrollaron símbolos y materiales compartidos, que fueron esenciales para las actividades ceremoniales importantes.

De otro lado, el análisis reveló la producción local de cerámica. Esto era evidente en la distribución de los tipos generales de tratamiento de la superficie externa, en particular la aplicación del engobe y el pulido vigoroso. El análisis estadístico mostró que hay diferencias significativas en la distribución espacial de estos dos atributos (Fig. 7). Por ejemplo, encontramos que en la concentración (norteña) de Pumamarka, las vasijas de servicio y las que no lo son típicamente muestran un pulido vigoroso, en tanto que en la concentración (al noreste) de Yanawara ambas no están pulidas. Las otras dos concentraciones contenían cantidades bastante parejas de vasijas que no eran de servicio y que mostraban dicho pulido. Es más, encontramos que en la concentración (al noroeste) de Kachiqhata, 
las vasijas que no son de servicio y las que sí lo son usualmente tienen engobe, diferenciando así a la muestra de esta concentración de todas las demás. Considerando las evidencias de una producción local junto con las similitudes en las técnicas decorativas, se hace evidente que los grupos locales de esta área produjeron variaciones locales de temas estilísticos regionales, lo que sugiere tanto el intercambio de ideas generales como el desarrollo de distinciones locales.

La arquitectura de las tumbas asimismo sugiere que grupos étnicos diferentes construyeron y habitaron las distintas concentraciones de asentamientos, y que también participaron en un estilo regional de actividad ceremonial en vías de desarrollo. Los arqueólogos hace tiempo señalaron que los espacios y las prácticas mortuorios reflejan los derechos que un grupo social tiene sobre un territorio, porque son los espacios locales significativos que constituyen los paisajes culturales (Barrett 1994; Renfrew 1976). Otros arqueólogos sostienen que el culto a los antepasados dentro de complejos de tumbas abiertas y encima de la superficie, fue una nueva práctica política que surgió en el área del Cusco y en la región andina entre los siglos XII y XIV (Bengsston 1998; Dean 2005; Hiltunen y McEwan 2004; Isbell 1997; McEwan et al. 2002). En el área de la prospección, estas tumbas sobre el suelo están distribuidas de modo homogéneo por toda la zona, lo que sugiere que los distintos grupos étnicos tomaban parte en ritos similares de culto a los antepasados (Kosiba 2011). Las tumbas de la FO se encuentran asociadas con los pueblos y fueron levantadas según criterios estilísticos específicos, lo que sugiere aún más que dichos poblados eran los centros de la vida ceremonial local.

Pero estas tumbas estuvieron caracterizadas por idiosincrasias estilísticas en su arquitectura. Hubo cuatro tipos de estas tumbas abiertas: tumbas en torres, en cistas, en acantilados y en cajas de pirca (Fig. 8). Las primeras son estructuras circulares o cuadradas de baja altura (1-1,5 m de alto), construidas con piedras no canteadas y que a menudo estaban coronadas con un techo de piedra escalonado. Las tumbas en cistas son muy parecidas a las torres, pero son mucho más pequeñas y semisubterráneas. Las tumbas en un acantilado lucen discretas portadas cortadas en éste, usualmente de aljez o cuarcita. Las tumbas en cajas de pirca son estructuras cuadradas hechas con piedras de campo y adobes, pintadas de color rojo. Los fechados radiocarbónicos de varias de estas estructuras de tumbas abiertas del área de Ollantaytambo, confirman que fueron construidas y usadas inicialmente en el siglo XII (Bengsston 1998). Las colecciones de superficie del PASW respaldan las fechas, indicando que los tiestos de la FO a menudo se encuentran asociados con las tumbas.

Estos estilos de tumbas diferencian claramente a las concentraciones de asentamientos, a pesar que no son exclusivos de concentraciones específicas (Fig. 9). Por ejemplo, las tumbas en torres se encuentran asociadas significativamente con ambas concentraciones dentro de la parte septentrional del área de Ollantaytambo, cerca del río Vilcanota (Llactallactayoq y Pumamarka-Markaqocha). Las tumbas en acantilados y en cistas caracterizan la parte meridional de la zona de la prospección, cerca de Wat'a. Las tumbas en cajas de pirca solamente se encuentran dentro del área de Yanawara. Estas diferencias estilísticas en la arquitectura mortuoria muy probablemente contribuyeron a una cultura política común: una forma compartida de reclamar una identidad social y/o una autoridad política locales. En otras palabras, en las décadas previas al dominio inka, la población de diversos poblados desarrolló un idioma político regional. Las tumbas, así como las conexiones entre los ancestros y los derechos locales, eran una forma regionalmente reconocible que los grupos sociales de la zona tenían para expresar su autonomía y autoridad locales. Al colocar sus tumbas en áreas específicas, la población conectaba su sangre con el suelo, afirmando así que su sitio ancestral (llacta) y sus alrededores eran las tierras inalienables de su grupo social.

Estos derechos sobre las tierras locales se encontraban asimismo arraigados en las actividades económicas cotidianas. Cada concentración de asentamientos contenía tanto sitios domésticos de menor escala como los poblados más grandes, lo que sugiere que la vida social, el trabajo y la religión eran coordinados localmente usando al ayllu o llacta como base. A lo largo de la prospección, la mayo- 

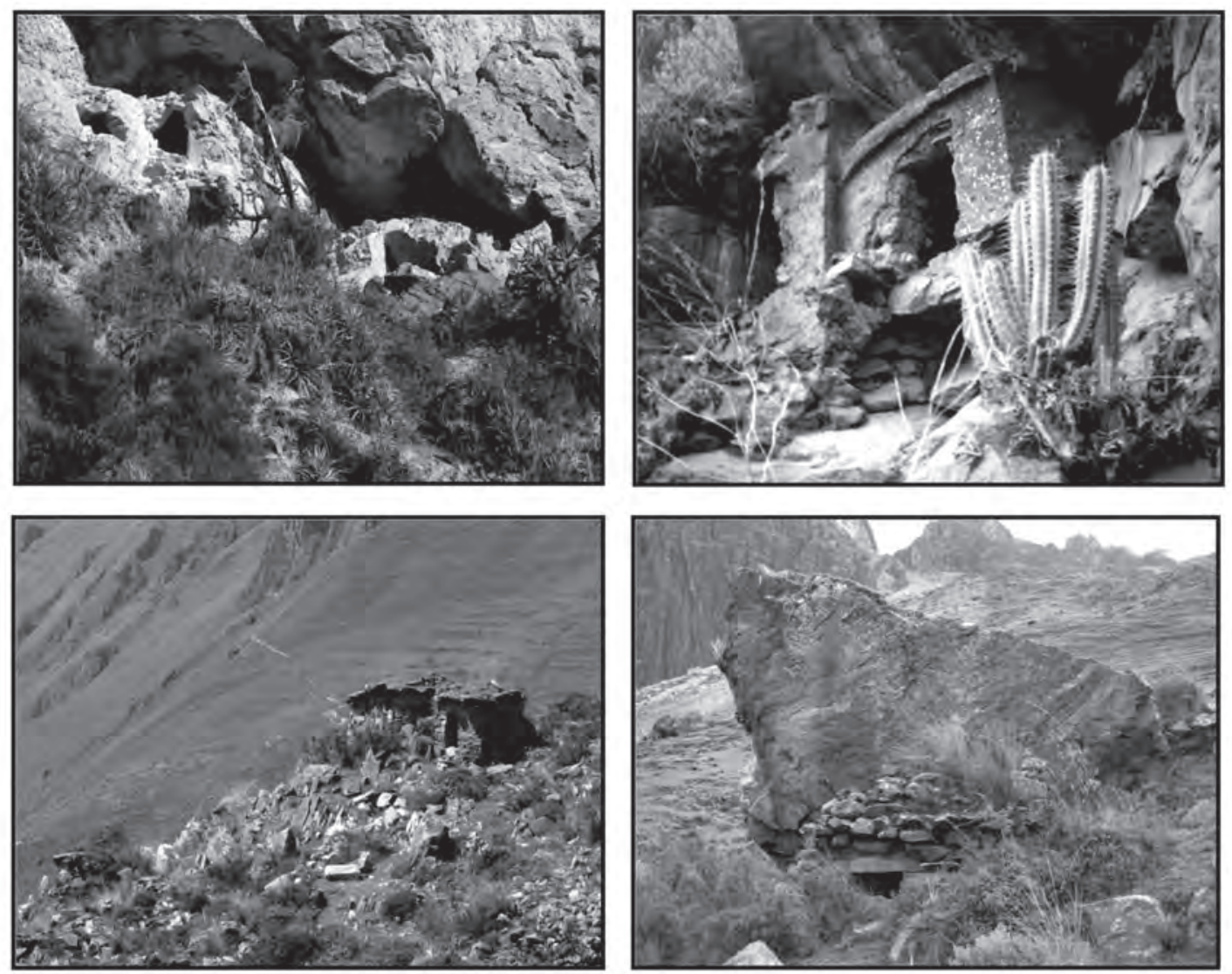

Figura 8. Las variaciones locales de un tema: aquí vemos a los tipos más comunes de tumbas abiertas, que fueron documentados en la zona de la prospección. Las tumbas de torre (abajo, a izquierda y derecha) estaban ubicadas a lo largo del río Vilcanota, y a menudo fueron construidas encima del suelo o junto a dos grandes peñascos. Las tumbas en los acantilados (arriba, a la izquierda) fueron documentadas frecuentemente en el cañón de Huarocondo, y usualmente están concentradas debajo de paredes de roca verticales. Las tumbas en cajas de pirca (arriba, a la derecha) fueron documentadas en el área de Yanawara, y fueron pintadas de rojo y colocadas sobre las laderas de los cerros y debajo de afloramientos rocosos.

ría de los sitios más pequeños (68\%) estaban ubicados a una corta caminata ( $500 \mathrm{~m})$ de maizales o de tierras de pastoreo en la alta puna. Su ubicación sugiere que estos sitios eran para actividades agrícolas o pastorales. Las colecciones de superficie indican que no eran lugares para actividades ceremoniales: tenían una alta densidad de vasijas utilitarias no decoradas de la FO, y una muy baja densidad de tiestos de vasijas de almacenaje o de servicio decoradas de dicha fase (en promedio, solamente el $11,1 \%$ de los tiestos recuperados en dichos sitios eran vasijas de servicio decoradas). Estos sitios no tienen tumbas o plazas de ningún tipo, lo que indica aún más que las actividades ceremoniales se llevaban a cabo en los pueblos.

En cambio todos los pueblos contienen evidencias de tipos distintivos de arquitectura, objetos y prácticas ceremoniales. Además de la presencia de estructuras de tumbas, plataformas y espacios de plazas, los poblados tenían altos porcentajes de vasijas de servicio decoradas (en promedio 43,4\% de los tiestos recuperados en estos sitios eran de este tipo). Los pueblos asimismo tenían estilos de cerámica de la FO que no fueron recuperados en ningún otro contexto, como vasijas negro y rojo sobre ante. En nuestras excavaciones en Wat'a -un pueblo y santuario preinkaiko ocupado durante largo 


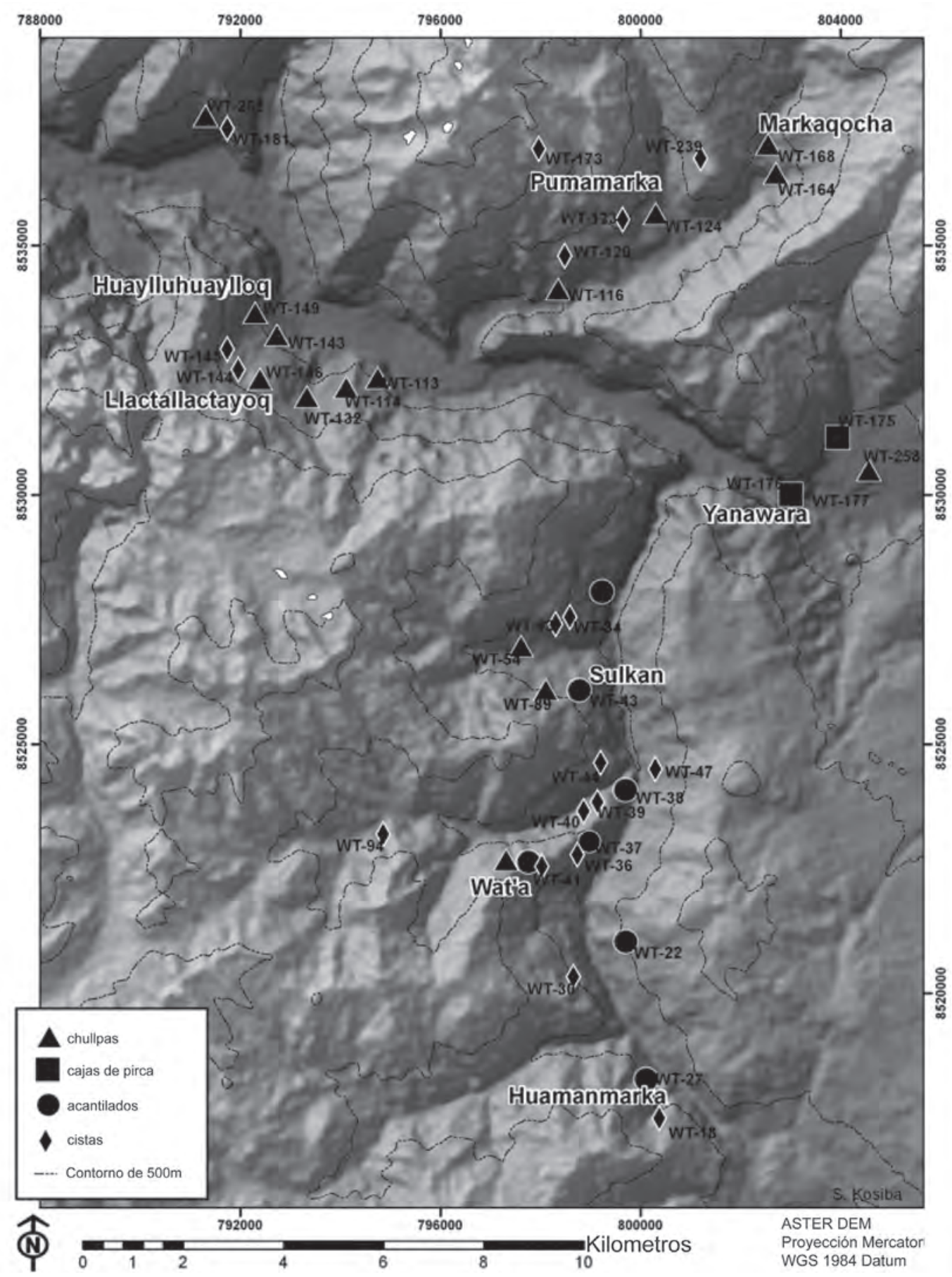

Figura 9. Este mapa muestra la distribución de los estilos arquitectónicos mortuorios en la zona de la prospección. Los diferentes estilos corresponden claramente a las distintas concentraciones de asentamientos, distinguiendo tal vez a los grupos sociales locales. 
tiempo-, encontramos dicho estilo en niveles que contenían altas densidades de vasijas de servicio decoradas y huesos de animales carbonizados, lo que sugiere que fueron desechadas junto con los materiales procedentes de las fiestas.

Todos los pueblos estaban situados sobre abruptas cumbres de cerros con conspicuas prominencias geomorfológicas. Sobre estas prominencias se levantaron terrazas concéntricas y plataformas, transformándolas así en pirámides escalonadas, empinadas y truncas (Fig. 10). Las colecciones de superficie del PASW recuperaron densidades muy altas de fragmentos de vasijas de servicio decoradas de la Fase Ollanta, en y alrededor de las prominencias, lo que sugiere que dichos espacios fueron usados en actividades no cotidianas y tal vez rituales. Es sumamente posible que las prominencias aterrazadas y los afloramientos rocosos asociados hayan sido wak'as que personificaban a la gente del poblado.

Además de estas diferencias en la arquitectura y los artefactos, los pueblos eran distintos de los sitios circundantes en lo que se refiere a la historia de su ocupación. Nuestras colecciones de superficie indican que todos estos asentamientos estuvieron ocupados de modo continuo o intermitentemente desde el Periodo Formativo, y que luego fueron ampliados y elaborados a lo largo de la FO. Las fechas de tres de estos pueblos coinciden con los datos de las colecciones de superficie. Por ejemplo, dos fechados radiocarbónicos de estratos profundos dentro de una de nuestras unidades de excavación en Wat'a, indican que este pueblo ya era un asentamiento activo en el
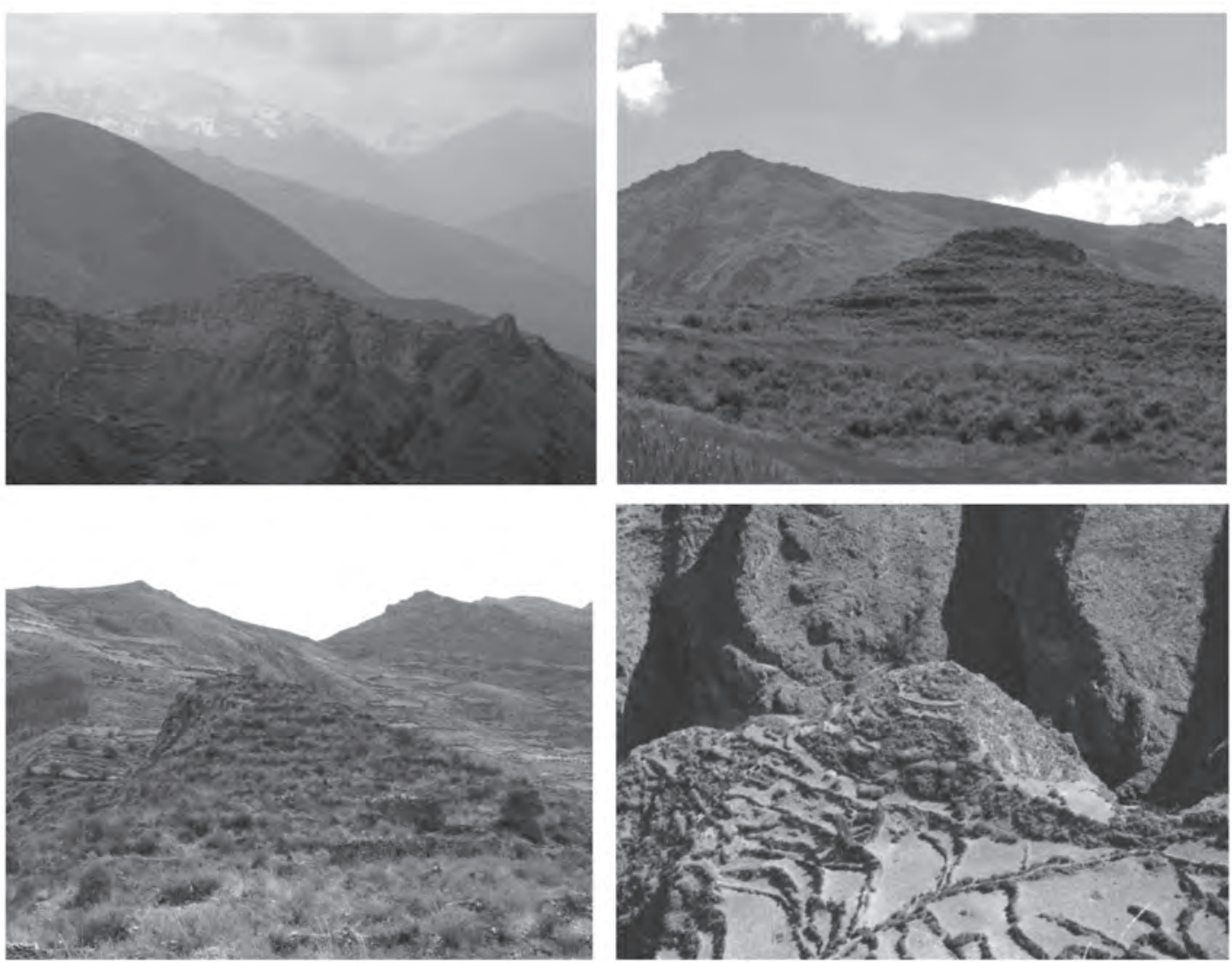

Figura 10. Varios centros políticos y rituales preinkaikos (de la Fase Ollanta) fueron levantados en torno a prominencias geomorfológicas marcadas. Estas prominencias fueron aterrazadas. En sentido horario desde arriba, a la izquierda: Wat'a, Sulkan, Markaqocha y Ankasmarka. 
primer milenio a.C. (véase Kosiba 2010). Del mismo modo, los fechados radiocarbónicos derivados de Pumamarka, Llactallactayoq y Kachiqhata sugieren que estos sitios fueron establecidos al menos mil años antes de la Fase Ollanta.

\begin{tabular}{|c|c|c|c|c|c|}
\hline Sitio & LAB no. & $\begin{array}{l}\text { Cerámica } \\
\text { asociada }\end{array}$ & $\mathrm{C} 14$ & Fuente & $\begin{array}{l}\text { Fecha } \\
(68.2 \%) \text { C.E. }\end{array}$ \\
\hline Pumamarka & SI6986 & & $940 \pm 40 \mathrm{BP}$ & Hollowell 1987 & $1020-1160$ \\
\hline Llactallactayoq & Q3090 & PITa & $915 \pm 50 \mathrm{BP}$ & Kendall 1996 & $1030-1190$ \\
\hline Wat'a & AA82091 & FO & $747 \pm 36 \mathrm{BP}$ & WAP & $1229-1285$ \\
\hline Wat'a & AA85885 & FO & $772 \pm 38 \mathrm{BP}$ & WAP & $1230-1299$ \\
\hline Pumamarka & SI6987 & & $710 \pm 55 \mathrm{BP}$ & Hollowell 1987 & $1250-1390$ \\
\hline Kachiqhata & Ua1709 & Inka & $700 \pm 65 \mathrm{BP}$ & Bengtsson 1998 & $1260-1390$ \\
\hline Pumamarka & $\begin{array}{l}\text { SI6988B } \\
\text { SI6988A }\end{array}$ & & $\begin{array}{l}645 \pm 45 \text { BP } \\
660 \pm 50 \text { BP }\end{array}$ & Hollowell 1987 & $\begin{array}{l}1295-1395 \\
1280-1390\end{array}$ \\
\hline Kachiqhata & SI6990 & & $640 \pm 55 \mathrm{BP}$ & Hollowell 1987 & $1295-1395$ \\
\hline
\end{tabular}

\section{Cuadro 2: Fechados radiocarbónicos publicados que corresponden a la Fase Ollanta.}

En suma, los pueblos y los asentamientos que les rodean representan la prolongación y la elaboración de una forma de vida agropastoral que se había desarrollado en esta zona a lo largo de milenios. Dentro de cada concentración, los sitios parecen estar dispuestos de modo complementario, como para coordinar las actividades socioeconómicas dentro de áreas inmediatas. Más en particular, las diferencias entre los sitios dentro de las concentraciones de asentamientos sugieren el desarrollo de comunidades complementarias, en las cuales la producción del maíz y otros bienes en asentamientos más pequeños, estuvo ligada a la reproducción tanto de la autoridad como de la sociedad, mediante las prácticas mortuorias y festivas en los pueblos. Sin embargo, las características comunes entre sitios en lo que a los rasgos estilísticos de los materiales ceremoniales se refiere -v.g. vasijas de servicio, tumbas y prominencias aterrazadas-, sugieren que no obstante la disposición local de los asentamientos, la población en esta área participaba en una red política regional, y un conjunto de símbolos compartidos.

Estos pueblos preinkaikos eran centros de política, ceremonialismo y actividades económicas locales. En contraste con muchas otras regiones andinas, dichos poblados no fueron establecidos abruptamente, en una época en la cual la población estaba en general desplazándose a localidades más altas (cf. Arkush 2007, 2009; Covey 2006; D’Altroy 1992; D’Altroy y Hastorf 2001). Ellos fueron percibidos durante largo tiempo como los centros de la vida ceremonial y económica local. Los pueblos eran lugares donde la gente llevaba los productos de los campos y pastizales vecinos -el maíz, las papas y la carne de llama- que habrían de ser consumidos allí y ofrecidos a los ancestros y wak'as del grupo étnico (Kosiba 2010). Cada uno de estos sitios probablemente era un componente esencial de un llaqta local, esto es una ecología a microescala que comprendía un pueblo, un medio ambiente local, los asentamientos asociados y un wak'a (cf. Murra 1980; Ramirez 2005). Transmitiendo una relación íntima entre la gente y los lugares, Salomon (1991: 23) señala que la población de un llaqta-el llaqtayoq- poseía un wak'a local y era poseída por éste. Los términos «wak'a, llaqta y llaqtayoq» expresaban así la esencia compartida de la localidad y la tierra, la sangre y el suelo.

En general, los datos de la prospección y la excavación revelan un paisaje preinkaiko en el cual la población local desarrolló un conjunto regionalmente reconocible de símbolos y formas arquitectónicas, en un intento de definir y defender sus derechos ancestrales sobre la tierra. De un lado, los datos 
confirman la propuesta de Rostworowski (1978) de que una forma incipiente de regionalismo, una red común de ideas y materiales intercambiadas, y una cultura política compartida, suministraron las bases del Estado inka. De otro lado, las disparidades en materiales, arquitectura y prácticas sociales sugieren que los pueblos mismos podrían haber sido residencias de la elite emergente y su parentela. Bajo esta luz, los datos asimismo coinciden con la teoría de Lumbreras (1978) de que la formación del Estado inka estuvo precedida por el desarrollo de nuevas y distintas posiciones de estatus. Veremos que la temprana autoridad inkaika parecería haber hundido sus raíces en este paisaje preinka, en particular en la conversión de dichos pueblos preinkaikos y la formalización de la cultura política preexistente.

\section{Transformaciones sociales durante el Periodo Inka Temprano}

Al examinar los cambios y continuidades en los patrones de asentamiento, podemos comenzar a comprender las transformaciones institucionales a través de las cuales la población de esta zona fue incorporada por vez primera a la formación política inka, y cómo dichos cambios fueron implementados dentro de sitios específicos. Por ejemplo, unos cambios dramáticos en la organización de los asentamientos podrían sugerir un programa de reestructuración política y económica decretado por el Estado y administrado centralmente. En cambio, las continuidades en la organización de los asentamientos y las sedes de poder podrían sugerir procesos más inclusivos, consistentes con un proyecto de consolidación de la estructura política.

A lo largo de esta sección usaremos el término «Periodo Inka Temprano» para referirnos al proceso inicial de consolidación del Estado inkaiko, que estuvo caracterizado por el uso de la cultura material inka clásico en actividades locales, y la aparición de arquitectura inkaika dentro de sitios preexistentes. En un «Periodo Imperial» se levantó la ciudad de Ollantaytambo, se canalizó el río Vilcanota y se construyeron sistemas masivos de terrazas. De este modo, en el presente estudio no se incluyen sitios posteriores e imperiales.

En general, la organización inkaika de los asentamientos y los patrones de uso de la tierra en el área de Ollantaytambo, reflejan la geografía social preexistente. El PASW documentó 187 sitios del Periodo Inka, 110 de los cuales no tenían evidencias de una ocupación de la FO (Fig. 11). Pero la mayoría de los nuevos asentamientos fueron construidos dentro de concentraciones de asentamientos de dicha fase. Es más, la inmensa mayoría (94\%) de los sitios preexistentes (FO) -incluyendo asentamientos, complejos de tumbas, santuarios y áreas agrícolas- continuó funcionando como lugares de actividad social y política. En realidad, muchos de los sitios de la FO $(41,3 \%)$ fueron embellecidos arquitectónicamente durante la transición al dominio inka. El abandono de los sitios quedó limitado a unos cuantos casos aislados. El mantenimiento de las concentraciones de asentamientos y sitios de la FO sugiere que los grupos sociales de esta zona mantuvieron su modo de vida a medida que eran incorporados al Estado inka.

Además, los datos de la prospección muestran amplias continuidades en las actividades socioeconómicas de uso de la tierra, desde la FO hasta el Periodo Inka. Independientemente del tamaño de los sitios, los del Periodo Inka estuvieron ubicados a alturas similares y cerca de las mismas tierras agropastorales que sus contrapartes más tempranas. No hay una diferencia estadística significativa entre la altura media de la muestra global de la FO y las muestras inkaikas, incluyendo todos los sitios del Periodo Inka ( $t=, 695, \mathrm{df}=205,7$, ninguna significación a un nivel alfa de 0,05). La altura media de todos los sitios FO es de 3439,1 m, la de todos los sitios del Periodo Inka es de 3390,7 m. La ubicación de los sitios también permaneció constante con respecto al terreno potencial de producción de maíz. Alrededor del 60\% de los sitios FO e inka se encuentran dentro o cerca de las tierras ideales de producción del maíz (TPM1), indicando así que la habitación de las áreas más bajas y cálidas caracterizó tanto a la FO como al Periodo Inka. Semejante continuidad en la altura y la ubicación de los asentamientos, sugiere la persistencia de una economía agropastoral local en el Periodo Inka temprano. 


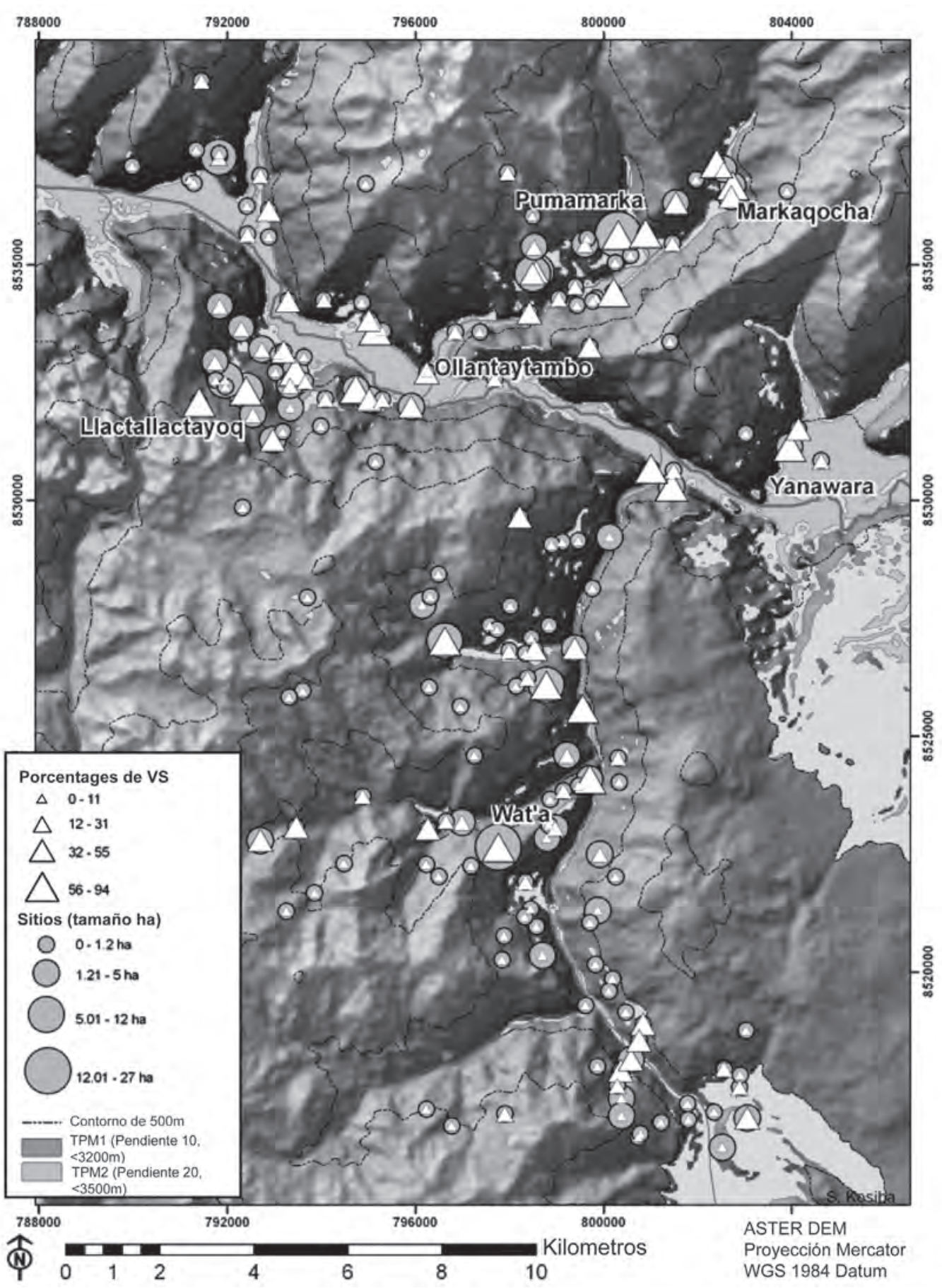

Figura 11. Este mapa presenta los patrones de asentamiento y la densidad de las vasijas de servicio en el Periodo Inka Temprano. Muchos asentamientos nuevos fueron ubicados en y cerca de concentraciones de asentamientos preexistentes. En los pueblos preinkaikos a menudo hallamos altas densidades de vasijas de servicio inka polícromo, lo que sugiere una continuidad en la ocupación y tal vez en la función de los lugares escogidos. 
La difundida continuidad en la historia de la ocupación y el uso de la tierra en el área de Ollantaytambo sugiere que, cuando la población de esta área fue incorporada al Estado inka, no lo fue mediante las estrategias típicamente asociadas con la expansión imperial posterior, a saber el movimiento de poblaciones, la desagregación y el abandono de los asentamientos (D'Altroy and Hastorf 2001). En realidad nuestros datos, y la persistencia y elaboración de los patrones de asentamiento precedentes en particular, son consistentes con prospecciones sistemáticas comparables del valle alto del Cusco, que encontraron poco o ningún cambio en la organización social durante las décadas iniciales del Periodo Inka (Bauer 1992, 2004; Bauer and Covey 2002). Los datos de Ollantaytambo sugieren un proceso de incorporación antes que de conquista. Entonces, lo que se requiere es considerar las estrategias de incorporación y cambio institucional que fueron específicos a esta región.

\section{Transformando el paisaje local, construyendo lugares inkas}

El proyecto reveló que sitios específicos de la Fo fueron a menudo elaborados arquitectónicamente en el transcurso de la transición al dominio inka, fundamentalmente a través de la construcción de una arquitectura inkaika formal, tales como plazas y edificios con nichos. Entre las muestras de todos los sitios de la FO, hay una relación estadísticamente significativa entre aquellos con una alta densidad de vasijas de servicio de esta fase, y los que tenían una alta densidad de vasijas de servicio inkaikas ( $r$ de Pearson $=, 217 ; n=83$; nivel de significación a 0,05). Esto sugiere el uso continuo de estos lugares como espacios donde escenificar eventos ceremoniales. Además, la arquitectura inkaika fue levantada dentro de sitios preexistentes para actividad ceremonial. Los sitios con alta densidad de vasijas de servicio de la FO contienen significativamente más edificios del Periodo Inka y más rasgos arquitectónicos inkaikos característicos como piedras angulares, portadas de doble jamba, nichos o ventanas trapezoidales.

Sin embargo, no todos los sitios de actividad ceremonial de la FO fueron convertidos en espacios ceremoniales inkas. Aunque sólo unos cuantos sitios de la FO $(5 / 81 ; 6 \%)$ fueron abandonados con el advenimiento del Periodo Inka, tres de ellos eran aldeas bastante grandes con una alta densidad de vasijas de servicio decoradas y sectores mortuorios (Yanawara, K'anaqchimpa y Tapara). Estos sitios fueron abandonados en tanto que muchos otros sitios comparables fueron ampliados o embellecidos, lo que sugiere que lo que influyó sobre la forma de incorporación de la población local al naciente Estado inka, fueron las diferencias particulares entre los pueblos que residían en distintos lugares, no así una transformación política uniforme como la conquista.

Queda de este modo claro que los espacios institucionales inkas fueron construidos primero dentro de sitios escogidos de la FO, especialmente los pueblos y aldeas que ya eran reconocidos como sedes de actividad ceremonial. Un estudio de cómo se estableció la gobernanza inkaika a medida que esta región iba siendo incorporada exige, por ello, prestar mayor atención a los sitios mismos.

\section{Cambios arquitectónicos del Periodo Inka en pueblos preinkaikos}

Durante el temprano Periodo Inka se construyeron macizas murallas de fortificación alrededor de partes de pueblos escogidos de la FO, en la que venía a ser una notable exhibición de poder. Un inmenso muro perimetral, que se extendía a lo largo de más de un kilómetro, rodeó a una serie de estructuras inkaikas monumentales recién levantadas en Wat'a, un gran ( 12 ha) pueblo de la FO ubicado sobre la escarpada cumbre de una montaña encima del valle de Huarocondo (Fig. 12). Del mismo modo se levantó una enorme muralla alrededor de un conjunto de edificios inkas en Pumamarka, un extenso ( 15 ha) pueblo de la FO en el valle de Patacancha (Fig. 12) (Kendall 1996; Niles 1980). En Wat'a, el muro perimétrico tiene atributos asociados con el canon arquitectónico inka, entre ellos portadas trapezoidales, una ligera inclinación interna de los muros y $90-110 \mathrm{~cm}$ de grosor. Ni las excavaciones del PASW ni las del INC junto al muro de Wat'a revelaron un antecedente preinkaiko. Los recientes 

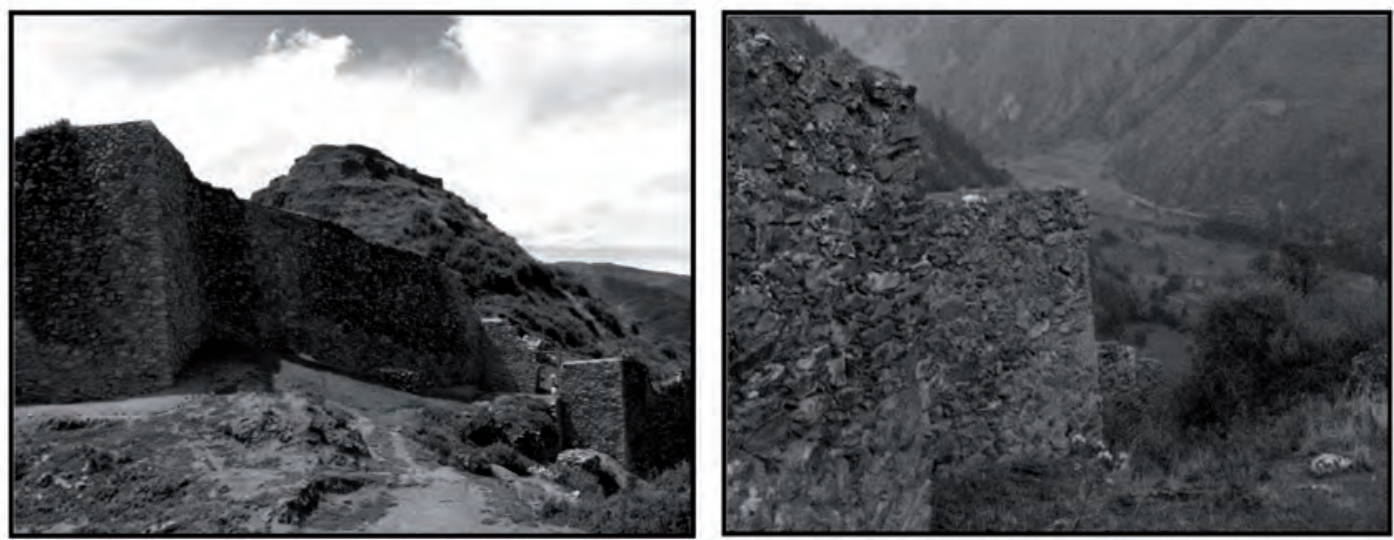

Figura 12. Durante el siglo XIV, la construcción de paredes correspondió a la construcción de plazas y salones con nichos en pueblos de la FO, como Wat'a (izquierda) y Pumamarka (derecha).

fechados radiocarbónicos confirmaron que las murallas de Wat'a y Pumamarka fueron construidas en el temprano siglo XV (Kosiba 2010). Éstas todavía tienen más de cinco metros de altura, lo que da fe de la solidez de su construcción, la escala a la que fueron levantadas y la impresión de poder que se quería que transmitieran.

Los arqueólogos hace tiempo que especulan con respecto a la función de las murallas perimétricas de los sitios preinkaikos e inkaikos. Los debates en torno a su función militar o ceremonial han persistido desde que la expedición de Hiram Bingham usara el término «instalación militar», para describir sitios como Ollantaytambo y Machu Picchu (Bingham 1911, 1930; Hyslop 1990). Los investigadores a menudo llaman a Wat'a un sitio militar, aludiendo a éste como una fortaleza de un pueblo autónomo que resistió el dominio inkaiko (Bauer 2004; Rowe 1946), o como una temprana ciudadela inka levantada a lo largo de la frontera del naciente Estado (Niles 1980). Otros sostienen que estas macizas murallas perimétricas inkaikas servían para separar y delimitar un área especial, limitando así el acceso a personas específicas y «codificando un paisaje [social] a partir del mero medio ambiente» (MacLean 1986: 83-86).

Estas posturas no son mutuamente excluyentes. Estas murallas probablemente fortificaban y sacralizaban el espacio, manifestando y protegiendo al mismo tiempo el orden social divino y/o las pretensiones aristocráticas del nuevo Estado. En otras palabras, es posible que estas murallas inkas, al igual que las murallas decoradas que cercaban los castillos de la Europa medieval o los pueblos fortificados de la Rajastán medieval (Coulson 2003; Sharma 1993), hayan tanto protegido como monumentalizado a los espacios y centros cortesanos que conformaban la temprana vida política inkaika.

En efecto, en Wat'a y Pumamarka las masivas murallas perimetrales rodean los sectores ceremoniales y marcan la importancia simbólica de dichas áreas (Figs. 13 y 14). Dentro de ellas hay amplios espacios de plazas, estructuras monumentales e instalaciones de almacenaje así como características distintivas de elite, como los baños de Pumamarka o las inmensas plataformas de Wat'a. Fuera de estas murallas hay concentraciones de arquetípicos patios residenciales y casas de la gente común del Periodo Inka. Esta rígida división en sectores residenciales y ceremoniales parecería haber sido esencial para la reconstrucción de Wat'a y Pumamarka.

En Wat'a, el nuevo sector monumental quedó comprendido íntegramente dentro de la muralla perimétrica, y este sector fue reconstruido en conformidad con una estética inkaika. Dentro de la muralla la escala de la arquitectura, los rasgos decorativos arquitectónicos y la organización espacial configuraron un espacio formal (Fig. 15). Al igual que en muchos prestigiosos sitios inkas, la aplicación de una escala monumental dio a las nuevas estructuras una naturaleza grandiosa. Los marcos de 


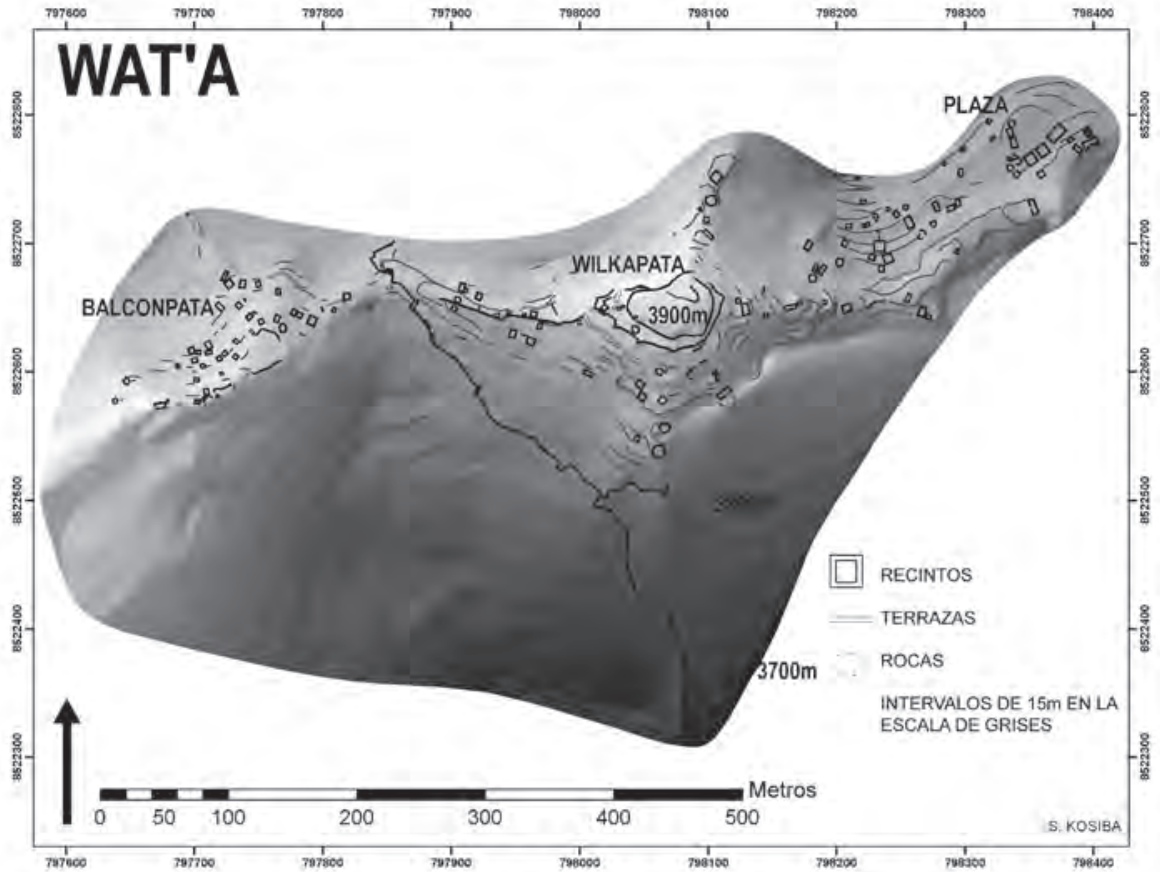

Figura 13. Plano de Wat'a, mostrando cómo distintos sectores residenciales fueron segregados espacialmente con su maciza muralla.

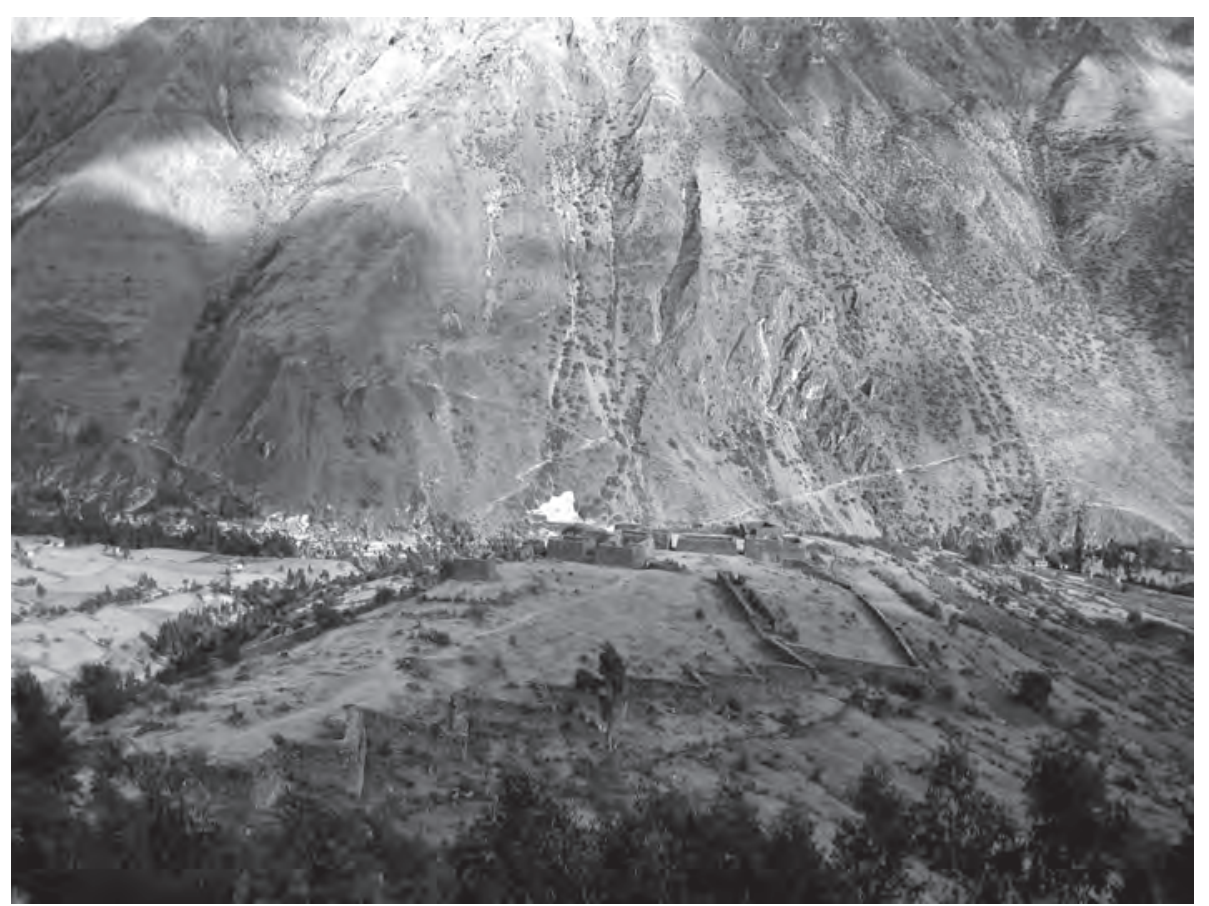

Figura 14. Plano de Pumamarka, ilustrando el sector ceremonial. El sector residencial se encuentra fuera de la enorme pared del sitio. 
las portadas, el área interna y el grosor de las paredes de estas estructuras a menudo tienen casi el doble del tamaño de lo que encontramos dentro de las casas inkaikas. Estos nuevos edificios fueron definidos aún más por símbolos reconocibles del poder y el prestigio inkaikos, como las portadas de doble jamba, las ventanas de doble vano, los nichos trapezoidales y las grandes puertas y ventanas.

Además de su escala y atributos arquitectónicos, las estructuras inkas de Wat'a crean un espacio exclusivo y formal restringiendo el acceso y el movimiento dentro del sitio. Desde las entradas guardadas en la imponente muralla perimetral a las rampas individuales usadas para acceder a plazas y plataformas, el desplazamiento dentro del sector ceremonial se encuentra altamente restringido, lo que refleja un plano espacial que buscaba dirigir y controlar el movimiento a lo largo de rutas preestablecidas. En todo el sector amurallado de Wat'a, unos senderos delineados con piedras dirigen el tráfico a lo largo de una secuencia de plataformas que se siguen la una a la otra sobre la cadena de cerros de Wat'a, como cuentas en un hilo (Fig. 16). Un inmenso edificio con nichos flanquea cada espacio de plataforma, sugiriendo así que éstas sostenían residencias de elite o espacios cívicos distintivos. La secuencia de plataformas termina en el espacio cívico monumental del sitio: una amplia plaza. Ésta yace sobre el área más alejada de la entrada y solamente es accesible desde un único punto.

Es más, recientes excavaciones efectuadas en Wat'a y Pumamarka indican que dichos sitios fueron transformados dramáticamente durante el temprano Periodo Inka. En Pumamarka, los arqueólogos advirtieron que este pueblo fue reconstruido y embellecido sistemática y selectivamente durante el periodo inkaiko (véase Kendall 1996; Niles 1980). Las excavaciones realizada en Wat'a suministraron detalles de cómo fue que estos sitios fueron reconstruidos, demostrando así que en este lugar, muchas de las estructuras inkas fueron levantadas encima de los restos de una densa aldea preinkaika. Complementando investigaciones anteriores (Cuba 2003, 2004), el PASW descubrió los vestigios arquitectónicos de estructuras residenciales y depósitos del Periodo Formativo y de la Fase Ollanta (Kosiba 2010, 2012).

En particular, al contrastar la versión que la elite inkaika daba de la caída de Wat'a, no hay ninguna evidencia arqueológica de que con el advenimiento del Periodo Inka, este sitio preinkaiko haya sido incendiado y arrasado por completo, o incluso abandonado. En realidad, las evidencias indican la destrucción selectiva, el embellecimiento monumental sistemático y la conversión arquitectónica del lugar. Nuestras 22 unidades de excavación fueron distribuidas a lo largo de los sectores ceremonial y residencial de intramuros y extramuros de Wat'a. Dichas unidades no descubrieron ninguna evidencia de un incendio que haya abarcado todo el sitio, como un lente general de cenizas, gran cantidad de enlucido y tierra quemada, o una alta densidad de objetos carbonizados (cf. Cuba 2003, 2004). Nuestras excavaciones encontraron fuegos altamente localizados y controlados, asociados específicamente con la construcción de la arquitectura inka. En lugar de reflejar la destrucción de Wat'a por obra de un triunfante ejército inka, los lentes de ceniza sugieren que se encendieron fuegos sumamente localizados a fin de iniciar y concluir una secuencia de prácticas ritualizadas de conversión y de retiro de servicio, que acompañaron el entierro de edificios de la FO y la erección de estructuras inkaikas (véase Kosiba 2012). Los fechados radiocarbónicos asimismo indican que Wat’a fue un importante poblado preinkaiko ocupado durante largo tiempo, que fue elaborado arquitectónicamente en el temprano periodo inka a medida que se le iba convirtiendo en un centro ceremonial fortificado. Las fechas procedentes de los niveles inferiores de la excavación en el espacio de la aldea preinkaika, bajo la plaza inka, dan fe de su larga historia de ocupación, indicando que algunos sectores fueron ocupados por vez primera hace más de dos mil años. ${ }^{5}$ Las fechas de contextos residenciales de la FO indican

5 Se derivaron tres medidas radiocarbónicas de contextos del Periodo Formativo. Estas tres medidas indican que Wat'a fue ocupada originalmente en los siglos VII y VIII a.E.C. Los rangos calibrados de estas tres fechas del Periodo Formativo son 3 a 118 E.C., 766 a 543 a.E.C., y 787 a 555 a.E.C. $(68,2 \%)$ (OxCal 4.1). 

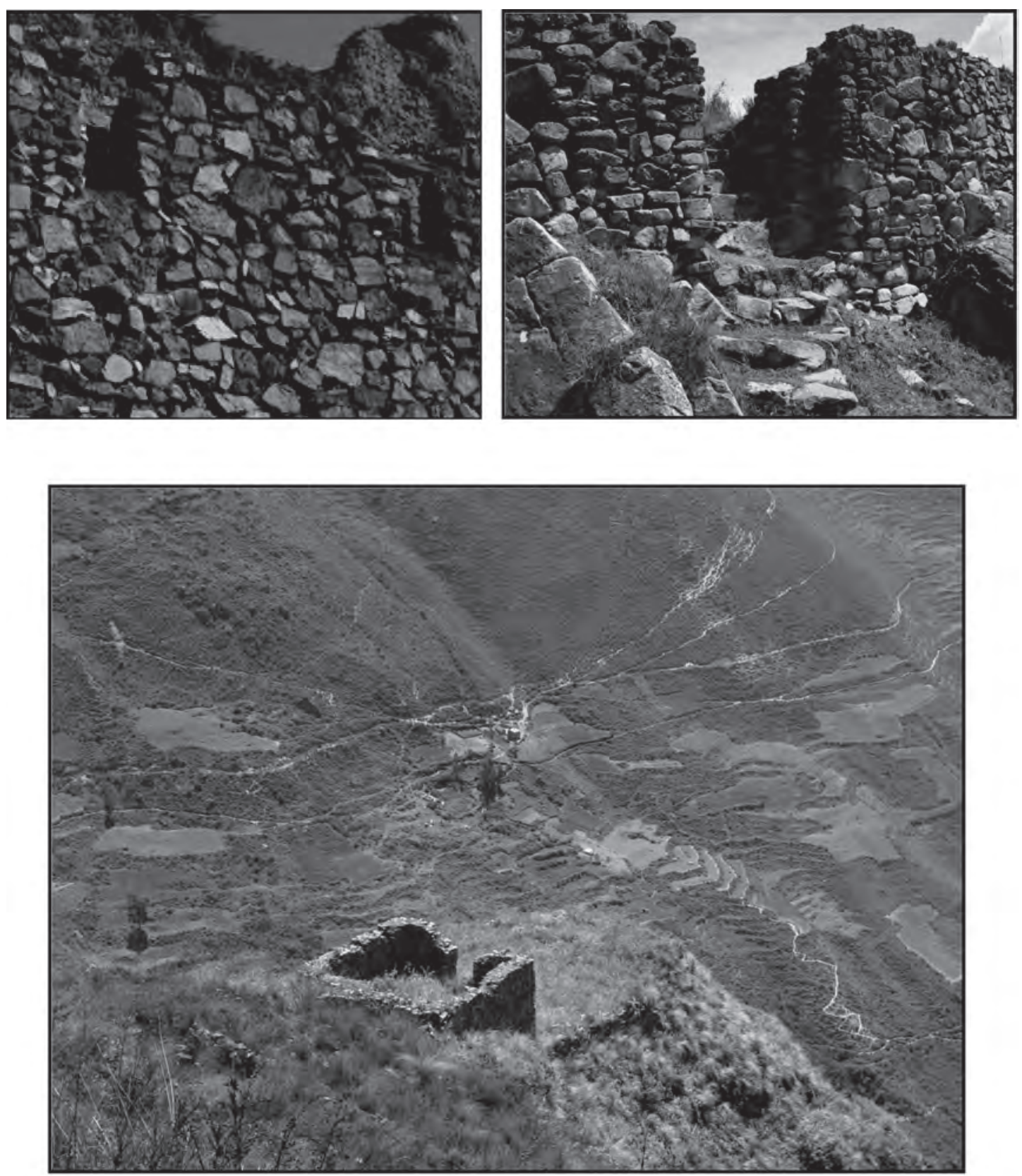

Figura 15. Aunque fueron construidas con materiales locales (arenisca), muchas estructuras de Wat'a contienen signos de prestigio incaicos como las ventanas de doble vano que adornan la estructura de almacenaje del periodo inka (arriba a la izquierda), y la portada de doble jamba que permite ingresar a un sector mortuorio (arriba, a la derecha). 


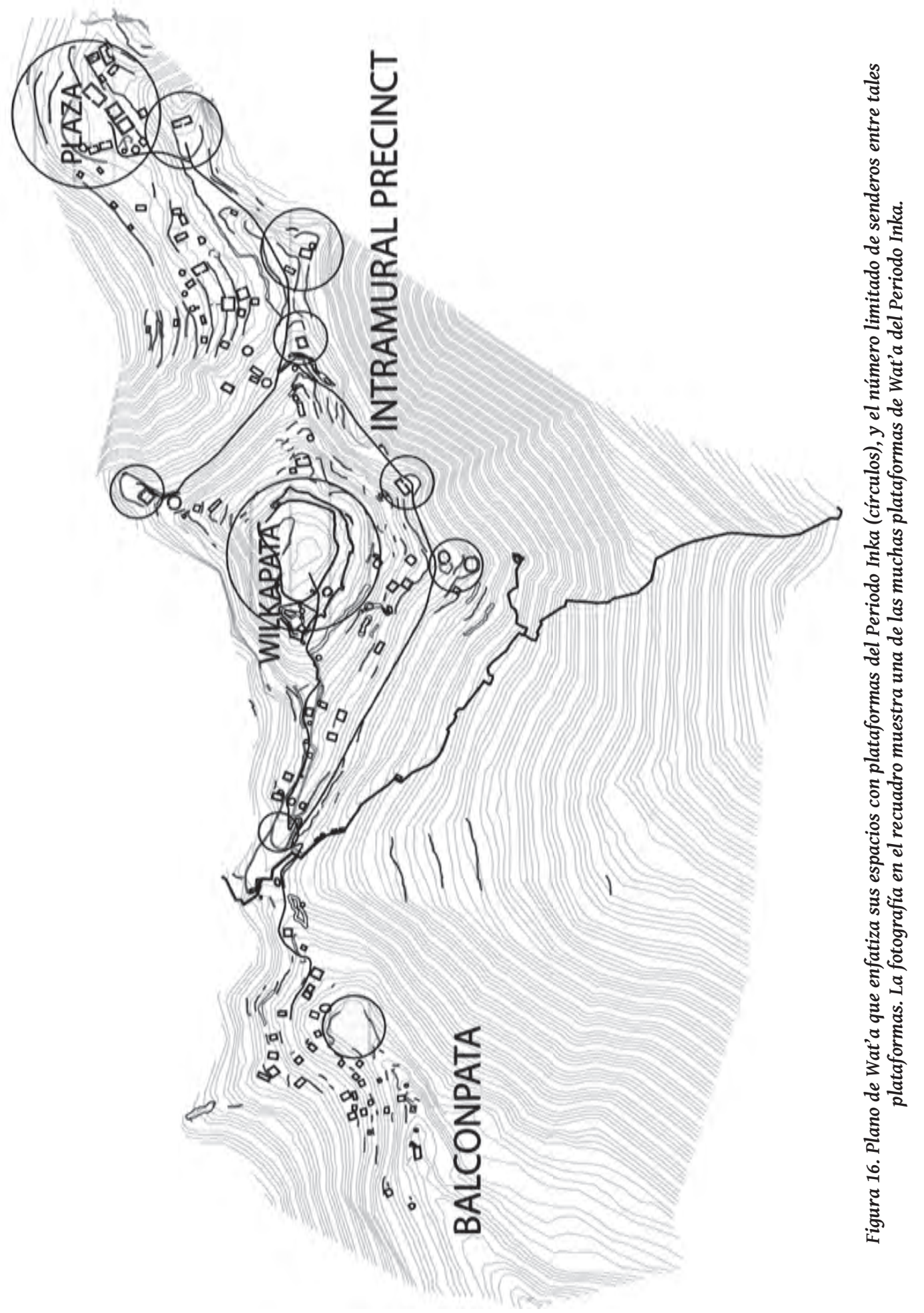


que las estructuras de dicha fase fueron construidas y habitadas durante el siglo XIII. ${ }^{6}$ Por último, las fechas del relleno encima de los contextos de la FO indican que estos espacios fueron convertidos en estructuras inkaikas en el siglo XIV.?

En general, entonces, las evidencias sugieren que la conversión de Wat'a fue el resultado de la transformación y la transferencia de poder político dentro del área de Ollantaytambo y no, como los inkas decían, la destrucción y el abandono de un lugar. Wat'a más bien fue reconstruido como un lugar inkaiko. Esta transformación requirió no sólo el embellecimiento de la arquitectura, sino también el cercado de los sectores monumentales recién construidos con murallas macizas. Es sumamente posible que al transformar Wat'a, un señor étnico local haya pasado a formar parte de la jerarquía social y política inkaika, tal vez un «inka de privilegio» de alto estatus. En efecto, el mantenimiento de los espacios ceremoniales locales sugiere la continuidad de las prácticas y de la vida social local en Wat'a. Podemos ver continuidades similares en la cultura material, los estilos arquitectónicos y las estructuras de las tumbas en otros sitios de la Fase Ollanta (v.g. Pumamarka), lo cual sugiere fuertemente que los señores locales de esta zona tal vez participaron deliberadamente en la formación del Estado inka, para así incrementar su estatus y promover sus propios intereses, definiendo marcadamente un nuevo tipo de autoridad de elite, formal y regional.

Volviendo a una perspectiva más regional, vemos que el embellecimiento de Wat'a no es sino un ejemplo de un proceso mucho más amplio de cambio social, que tuvo lugar dentro de sitios selectos de toda la región del Cusco. En Pumamarka se construyó un inmenso barrio amurallado sobre la ladera de un cerro adyacente a un amplio asentamiento preinkaiko. En la región al norte del Cusco, en Q'aqya Qhawana (Juchuy Coscco), se erigieron grandiosas estructuras monumentales inkaikas, a las que se separó de un sector residencial para la gente común (Kendall et al. 1992). En Qhapaq Kancha, en la región al noreste del Cusco, se levantó una plaza inka sobre una aldea preexistente (Covey 2006), en forma asombrosamente similar a la superposición arquitectónica de Wat'a. Se construyeron edificios inkaikos con nichos y plazas dentro del sector central de varios grandes poblados preinkaikos como Pukara Pantillijlla, donde las estructuras monumentales inkas conforman un núcleo alrededor del cual se concentran las estructuras residenciales más tempranas (Covey 2006). Sin embargo, otros sitios preinkaikos fueron al mismo tiempo abandonados o destruidos. Estos datos regionales sugieren aún más que la autoridad inkaika fue definida inicialmente mediante el control de espacios para actividades políticas y ceremoniales.

\section{CONCLUSIONES: TRANSFORMANDO EL PAISAJE, EMPLAZANDO LA AUTORIDAD}

Los datos del PASW señalan que los inkas arraigaron su autoridad en el paisaje social precedente. Al reflexionar sobre los datos correspondientes a los siglos directamente anteriores a la formación del Estado inkaiko, vemos cómo un área a la cual ellos describieron como la provincia de la barbarie caótica, tuvo en realidad un orden social y cultural regional. En efecto, múltiples formaciones políticas aparecieron, coexistieron y declinaron antes del auge de los inkas. Ninguna formación política individual parece haber controlado más recursos que otras, o tenido más influencia política. En realidad, cada una de ellas operó de distintas formas para conservar sus derechos sobre tierras, lugares y recursos locales. En general, los pueblos dentro de cada una de estas formaciones políticas decoraron sus vasijas de servicio con motivos y símbolos que invocaban un estilo regional de la cultura material («killk'e»), lo cual sugiere que tomaban parte en una cultura sincrética y en una red de interacción re-

6 En Wat'a se derivaron dos medidas radiocarbónicas de contextos de la Fase Ollanta. Estas dos medidas indican que ésta fue una aldea de la FO, ocupada durante el siglo XIII E.C. Los rangos calibrados de estas dos fechas de la FO son 1230 a 1299 E.C.y 1229 a 1285 E.C. $(68,2 \%)$ (OxCal 4.1).

7 Los datos de la excavación no fueron incluidos en este artículo debido a las limitaciones de espacio, pero véase Kosiba $(2010,2012)$ y un artículo de Kosiba y Galiano a publicarse en español. 
gional. Más específicamente, las evidencias arqueológicas demuestran que las elites locales desarrollaron un nuevo tipo de autoridad que tenía su base en centros ceremoniales como Wat'a y Pumamarka, donde gozaban de un acceso privilegiado a espacios rituales y objetos a los que valoraban. Estas elites buscaron definir aún más su estatus produciendo una serie de objetos y espacios: vasijas de servicio con los diseños comunes de killk'e, prominencias aterrazadas y tumbas individuales abiertas. Al igual que los castillos y la heráldica de la Europa medieval o de Rajastán, estos objetos y espacios distintivos conformaron un estilo regionalmente reconocible, a través del cual las elites locales difundieron y significaban su derecho a la autoridad y la autonomía locales. Si bien es posible que hayan habido ciertos conflictos entre grupos sociales, parecería que antes del surgimiento del Estado inka hubo un alto grado de comunicación social, afiliación cultural e interacción entre las elites regionales.

Estos nuevos materiales, lugares y prácticas de elite pasaron a ser las bases del Estado inka. Es posible que jamás sepamos si fueron las elites locales de la región cuzqueña, o los inkas del Cusco mismo, quienes dirigieron los cambios e inventaron las tradiciones a través de las cuales nació el Estado. Pero lo que sí queda claro es que el temprano Estado inka transformó estas tradiciones culturales precedentes y adoptó las formas preexistentes del estatus de elite. En primer lugar, los sitios ancestrales y los centros de elite «tradicionales» fueron convertidos en centros ceremoniales inkas fortificados. En segundo lugar, las actividades ceremoniales se hicieron exclusivas y quedaron limitadas a lugares específicos dentro de un paisaje inka definido marcadamente (Mitchell 1988; Scott 1998; Smith 2003).

Al establecer espacios políticos inkaikos dentro de lugares ya reconocidos, su autoridad quedó así revestida de un conjunto de prácticas culturales surgidas en una época anterior. Los datos sugieren que el temprano régimen inka reivindicó su autoridad específicamente escenificando conspicuas fiestas dentro de lugares preinkaikos. Al escenificar dichas fiestas en estos lugares, los inkas y/o las elites recién emergidas afirmaron su dominio absoluto sobre los lugares y actividades que definían la autoridad política. Ellos declararon que solamente ciertos lugares y actividades eran «políticos». De este modo, las prácticas y lugares del paisaje preexistente fueron convertidos estratégicamente en instrumentos del dominio inka. Dicho de modo simple, un paisaje inkaiko se fue generando a medida que los símbolos y espacios de una nueva autoridad de elite inka iban siendo emplazados dentro de los confines sagrados de los sitios ancestrales de los pueblos preinkas.

Estos resultados plantean un reto empírico para las versiones Cusco-céntricas de la formación estatal. El Estado inka y sus instituciones no fueron simplemente la invención de un solo grupo privilegiado o de una única persona proveniente de fuera del Cusco. Ni tampoco fue una simple aplicación del aparato institucional o la ideología, largo tiempo latente, de Wari o Tiwanaku. Además, la gobernanza inkaika no fue una mera prolongación de prácticas, normas y valores generales andinas. Los inkas más bien buscaron conservar los principios de autoridad que se desarrollaron durante el Periodo Intermedio Tardío. Pero hicieron esto convirtiendo y embelleciendo sedes preexistentes del poder político. Las elites que tomaron parte en el desarrollo del temprano Estado inkaiko buscaron controlar, elaborar y formalizar los materiales, lugares y actividades de la época anterior, transformando así su idioma político en un orden social formal. Parecería que las bases de la autoridad inka fueron establecidas delimitando y controlando los espacios de la práctica política dentro de entornos locales escogidos.

Al investigar los procesos a través de los cuales las poblaciones locales fueron incorporadas inicialmente al Estado inka, este artículo ha mostrado cómo los lugares locales, y sus historias, fueron esenciales para el surgimiento de un extenso imperio. El cambio político se dio dentro de espacios locales íntimos, así como en los amplios bulevares y espaciosas plazas de las ciudades capitales. Examinar los procesos a través de los cuales un lugar sagrado o políticamente significativo se transforma o redefine, es averiguar cómo es que los regímenes políticos intentarán asegurar su autoridad reconfigurando los paisajes. La autoridad política no se produce dentro del aparato administrativo de un Estado, ni tampoco se emana simplemente de una tradición cultural general. Ella más bien es 
constituida en las actividades y lugares locales a través de los cuales las personas perciben y experimentan su mundo. Tales lugares no son, en realidad, telones de fondo pasivos de los eventos políticos, sino lugares disputados cuyo control puede constituir o subvertir las bases de la autoridad regional del Estado.

\section{BiBLIOGRAFÍA}

ALCINA FRANCH, J.

1978 «Ingapirca: aquitectura y áreas de asentamiento». Revista de Antropología Americana 8: 127-146.

ALCOCK, S. E.

2002 Archaeologies of the Greek Past:Landscape, Monuments, and Memories. Cambridge: Cambridge University Press.

ANDRUSHKO, V.\& TORRES, E.

2011 «Skeletal Evidence for Inka Warfare from the Cusco Region of Peru». American Journal of Physical Anthropology 146: 361-372.

ANSCHUETZ, K. F., WILHUSEN, R. H., \& SCHEICK, C. L.

2001 «An archaeology of landscapes: perspectives and directions». Journal of Archaeological Research 9: 157-211.

ARKUSH, E.

2005 Colla Fortified Sites: Warfare and Regional Power in the Late Prehispanic Titicaca basin, Peru. Unpublished Dissertation, University of California Los Angeles, Los Angeles.

ARKUSH, E., \& STANISH, C.

2005 «Interpreting conflict in the ancient Andes: implications for the archaeology of warfare». Current Anthropology 46(1): 3-28.

ASHMORE, W., \& KNAPP, B.

1999 Archaeologies of Landscape: Contemporary perspectives. Oxford: Basil Blackwell.

BARRETT, J. C.

1994 Fragments from Antiquity: An Archaeology of Social Life in Britain, 2900-1200 B.C. Oxford: Blackwell Publishers.

BAUER, B. S.

1992 The Development of the Inka State. Austin: University of Texas Press.

2002 Las antiguas tradiciones alfareras de la región del Cusco. Cusco: Centro Bartolomé de las Casas.

2004 Ancient Cusco: Heartland of the Inka. Austin: University of Texas Press.

BAUER, B. S., \& COVEY, R. A.

2002 «State Development in the Inka Heartland (Cusco, Peru)». American Anthropologist 10(3): 846-864.

BAUER, B. S., \& STANISH, C.

2001 Ritual and Pilgrimage in the Ancient Andes: The Islands of the Sun and Moon. Austin: University of Texas Press.

BENGSSTON, L.

1998 «Prehistoric stonework in the Peruvian Andes: A case study at Ollantaytambo.» En: GOTARC series B 10, Ethnologiska studier. Goteborg: Ethnografiska museet.

BRAY, T. L.

2003 «Inka Pottery as Culinary Equipment: Food, Feasting, and Gender in Imperial Design». Latin American Antiquity 14(1): 3-28.

BRUNDAGE, B. C.

1963 Empire of the Inka. Norman: University of Oklahoma Press.

BRUSH, S. B.

1976 «Man's use of an Andean ecosystem» Human Ecology 4(2): 147-166. 
BURGER, R., \& SALAZAR, L.

2004 Machu Picchu: Unveiling the Mystery of the Inkas. New Haven: Yale University Press.

CHATFIELD, M.

2007 From Inka to Spanish Colonial: Transitions in Ceramic Technology. Unpublished Ph.D. Dissertation, University of California, Santa Barbara, Santa Barbara.

CHATFIELD, M.

2010 «Tracing Firing Technology through Clay Properties in Cusco, Peru». Journal of Archaeological Science 37: 727-736.

CIEZA DE LEÓN, P. D.

1971 [1554] La Crónica del Perú. Bogotá: Ediciones de la Revista Ximenez de Quesada.

COBEN, L.

2006 «Other Cuscos, Replicated Theaters of Inka Power.» En: T. Inomata \& L. Coben (eds.), Archaeology of Performance: Theaters of Power, Community, and Politics. Lanham, MD: Altamira Press.

COBO, B. D.

1990 [1653] Inka Religion and Customs. Austin: University of Texas Press.

COSTIN, C. L., \& EARLE, T. K.

1989 «Status Distinction and Legitimation of Power as Reflected in Changing patterns of Consumption in Late Prehispanic Peru». American Antiquity 54(4): 691-714.

COULSON, C.

2003 Castles in Medieval Society: Fortresses in England, France, and Ireland in the Central Middle Ages. Oxford: Oxford University Press.

COVEY, R. A.

2006 How the Inkas Built their Heartland: State Formation and the Innovation of Imperial Strategies in the Sacred Valley, Peru. Ann Arbor: University of Michigan Press.

2008 «Multiregional Perspectives on the Archaeology of the Andes during the Late Intermediate Period (c. A.D. 1000-1400)». Journal of Archaeological Research 16: 287-338.

CUBA PEÑA, L. A.

2003 Informe de Investigación Arqueológico Wat'a - Warokondo. Cusco: Instituto Nacional de Cultura (INC).

2004 Informe de Investigación Arqueológico Wat'a - Warokondo. Cusco: INC.

CUMMINS, T. B. F.

2002 Toasts with the Inka: Andean Abstraction and Colonial Images on Quero Vessels. Ann Arbor: University of Michigan Press.

D'ALTROY, T. N.

1992 Provincial Power in the Inka Empire. Washington: Smithsonian Institution Press.

1994 «Public and Private Economy in the Inka Empire.» En:E. M. Brumfiel (ed.), The Economic Anthropology of the State: 169-221. New York: University Press of America.

D'ALTROY, T. N., \& HASTORF, C.

2001 Empire and Domestic Economy. New York: Kluwer Academic.

DAVID, B., \& THOMAS, J.

2010 Handbook of landscape archaeology. Walnut Creek: Left Coast Press.

DEAN, E. M.

2005 Ancestors, Mountains, Shrines, and Settlements: Late Intermediate Period Landscapes of the Southern Vilcanota Valley, Peru. Unpublished Ph.D. Dissertation, University of California, Berkeley.

DWYER, E. B.

1971 The Early Inka Occupation of the Valley of Cusco, Peru. Unpublished Ph.D. Dissertation, University of California, Berkeley.

ESTETE, M. D.

1918 [1535] Noticia del Perú, En: Boletín de la Sociedad Ecuatoriana de Estudios Históricos Americanos, Tomo 1, No.3 (pp. 312-335). Quito. 
FARRINGTON, I. S., \& ZAPATA, J.

2003 «Nuevos canones de arquitectura inka: investigacioones en el sitio de Tambokancha - Tumibamba, Jaquijahuana, Cusco». En: P. Kaulicke, G. Urton y I. Farrington (eds.), Identidad y Transformacion en el Tawantinsuyu y en los Andea Coloniales: Perspectivas Arqueologicas y Etnohistoricas, Segunda Parte. Lima: Boletin de Arqueología PUCP 7: 57-78.

GADE, D. W.

1975 Plants, Man, and Land in the Vilcanota Vallley of Peru. The Hague: Dr. W. Junk B.V.

GALIANO BLANCO, V. \& MARINA APAZA BUSTAMANTE, L.

2004 Arqueologia de Ollantaytambo - Manyaraki: Una Introduccion a su Estudio. Tesis, Facultad de Ciencias Sociales, Cusco: Universidad de San Antonio Abad del Cusco.

GARCILASO DE LA VEGA, E. I.

1965 [1605] Los Comentarios Reales de los Inkas. En: C. Sáez de Santa María (ed.), Obras Completas, Biblioteca de Autores Españoles, v. 132-135. Madrid: Ediciones Atlas.

GASPARINI, G., \& MARGOLIES, L.

1980 Inka Architecture. Bloomington: University of Indiana Press.

GIBAJA OVIEDO, A. M.

1982 «La ocupacion neoinka del valle de Urubamba». En: I. Oberto (ed.), Arqueología de Cusco. Cusco: INC.

1984 «Requencia cultural de Ollantaytambo». En: A. E. Kendall (ed.), Current Archaeological Projects in the Central Andes, BAR International Series 210. Oxford: British Archaeological Reports.

GUAMAN POMA DE AYALA, F.

1980 [1615] El primer nueva crónica y buen gobierno. Mexico: Siglo Veintiuno.

HAQUEHUA HUAMAN, W., \& MAQQUE AZORSA, R.

1996 Cerámica de Cueva Mogo-Maras. Tesis, Facultad de Ciencias Sociales, Cusco: Universidad de San Antonio Abad del Cusco.

HASTORF, C.

1993 Agriculture and the Onset of Political Inequality before the Inka. Cambridge: Cambridge University Press.

2001 «Agricultural Production and Consumption». En: T. N. D’Altroy \& C. Hastorf (eds.), Empire and Domestic Economy: 155-178. New York: Kluwer Academic Press.

2003 «Andean luxury foods: special food for the ancestors, deities and the élite.» Antiquity: 545-554.

HEFFERNAN, $\mathrm{K}$.

1989 Limatambo in Late Prehistory: Landscape Archaeology and Documentary Images of Inka Presence in the Periphery of Cusco. Unpublished Ph.D. Dissertation. Australian National University, Canberra.

1996 Limatambo: Archaeology, History and the Regional Societies of Inka Cusco. BAR International Series 644, Oxford: British Archaeological Reports.

HILTUNEN, J., \& MCEWAN, G. F.

2004 «Knowing the Inka Past». En: H. Silverman (ed.), Andean Archaeology: 237-254. Malden: Blackwell.

HOLLOWELL, J. L.

1987 Precision Cutting and Fitting of Stone in Prehistoric Andean Walls. Washington D.C.: National Geographic Society.

HYSLOP, J.

1990 Inka Settlement Planning. Austin: University of Texas Press.

ISBELL, W. H.

1997 Mummies and Mortuary Monuments: A Post-Processual Prehistory of Andean Social Organization. Austin: University of Texas Press.

JENNINGS, J.

2004 «La Chichera y El Patron: Chicha and the Energetics of Feasting in the Prehistoric Andes.» Archaeological Papers of the American Anthropological Association 14: 241-259. 
JULIEN, C.

2000 Reading Inka History. Iowa City: University of Iowa Press.

KENDALL, A. E.

1984 "Archaeological Investigations of Late Intermediate Period and Late Horizon Period at Cusichaca, Peru.» En: A. Kendall (ed.), Current Archaeological Projects in the Central Andes: 247-290. Oxford: British Archaeological Reports.

KENDALL, A. E.

1985 Aspects of Inka Architecture: Description, Function, and Chronology, parts 1 and 2. BAR International Series 242. Oxford: British Archaeological Reports.

1988 «Inka Planning North of Cusco between Anta and Machu Picchu and along the Urubamba Valley.» En: N. J. Saunders \& M. O. de (eds.), Recent Studies in Precolumbian Archaeology. Oxford: BAR.

1994 Proyecto Arqueológico Cusichaca, Cusco: Investigaciones arqueológicas y de rehabilitación agrícola, tomo I. Lima: Southern Peru Copper Corporation.

1996 «An Archaeological Perspective for Late Intermediate Period Inka Development.» Journal of the Steward Anthropological Society 24(1-2): 121-156.

KENDALL, A. E., EARLY, R., \& SILLAR, B.

1992 «Report on archaeological field season investigating early Inka architecture at Juchuy Coscco (Q'aqya Qhawana) and Warq'ana, Province of Calca, Department of Cusco, Peru.» En: N. J. Saunders (ed.), Ancient America: Contributions to New World Archaeology: 189-256. Oxford: Oxbow Books.

KOSIBA, S.

2010 Becoming Inka: The Transformation of Political Place and Practice during Inka State Formation (Cusco, Perú). Unpublished Ph.D. Dissertation. Department of Anthropology, University of Chicago, Chicago.

2011 «The Politics of Locality: Pre-Inka Social Landscapes of the Cusco Region» En: P. Johansen y A. Bauer, (eds.), The Archaeology of Politics: The Materiality of Political Practice and Action in the Past: 114150. Cambridge: Cambridge Scholars Publishing.

2012 «Emplacing Value, Cultivating Order: Places of Conversion and Practices of Subordination throughout Early Inka State Formation (Cusco, Perú)» En: G. Urton y J. Papadopoulos, (eds). Constructions of Value in the Ancient World. Cotsen Institute of Archaeology, Los Angeles.

KOSIBA, S. \& A. BAUER.

2013 «Mapping the Political Landscape: Toward a GIS Analysis of Social and Environmental Difference». Journal of Archaeological Method and Theory 20(1): 61-101.

LEVILLIER, R.

1940 Don Francisco de Toledo, Supremo Organizador del Perú, Su Vida, Su Obra (1515-1582). Tomo II: Sus informaciones sobre los inkas (1570-1572). Buenos Aires: Espasa-Calpe.

LITTLE, P.E.

1999 Environments and environmentalism in anthropological research: Facing a new Millennium. Annual Review of Anthropology. 28: 253-284.

LUMBRERAS, L. G.

1978 «Acerca de la aparición del estado Inka.» En: M. M. Ramiro (ed.), Actas y trabajos del III congreso peruano «El hombre y la cultura andina» 1: 101-109. Lima: Universidad Nacional Mayor de San Marcos.

LUNT, S. W.

1984 "An introduction to the pottery from the excavations at Cusichaca, Department of Cusco, Peru.» En: A. E. Kendall (ed.), Current Archaeological Projects in the Central Andes: Some Approaches and Results: 302-322. Oxford: British Archaeological Reports.

1987 Inka and pre-Inka Pottery: Pottery from Cusichaca, Department of Cusco, Peru. London: University of London.

MACLEAN, M. G.

1986 Sacred Land, Sacred Water: Inka Landscape Planning in the Cusco Area. Unpublished Ph.D. Dissertation, University of California, Berkeley. 
MCEWAN, G. F.

1987 The Middle Horizon in the Valley of Cusco, Peru: The Impact of Wari Occupation of the Lucre Basin. BAR International Series, 372. Oxford: British Archaeological Reports.

1991 «Investigations at the Pikillacta Site: A Provincial Huari Center in the Valley of Cusco.» En: W. H. Isbell y G. F. McEwan (eds.), Huari Administrative Structures: Prehistoric Monumental Architecture and State Government. Washington DC: Dumbarton Oaks.

1996 «Archaeological Investigations at Pikillacta, a Wari Site in Peru.» Journal of Field Archaeology 23(2): 169-186.

1998 «The Function of Niched Halls in Wari Architecture». Latin American Antiquity 9(1): 68-86.

2005 Pikillacta: The Wari Empire in Cusco. Iowa City: University of Iowa Press.

2006 The Inkas: New Perspectives. Santa Barbara: ABC Clio.

MCEWAN, G. F., CHATFIELD, M., \& GIBAJA OVIEDO, A.

2002 «The Archaeology of Inka Origins: Excavations at Chokepukio, Cusco, Peru.» En: W. Isbell \& H. Silverman (eds.), Andean Archaeology 1: Variations of Sociopolitical Organization: 287-301. New York: Kluwer Academic.

2008 «Arquitectura monumental en al Cusco del Periodo Intermedio Tardio: Evidencias de continuidades en la reciprocidad ritual y el manejo de administrativo entre los horizontes Medio y Tardio.» Boletín de Arqueología PUCP, 9: 257-280.

MCEWAN, G. F., GIBAJA OVIEDO, A., \& CHATFIELD, M.

1995 "Archaeology of the Chokepukio Site: An Investigation of the Origin of the Inka Civilization in the Valley of Cusco, Peru. A Report of the 1994 Field Season.» Tawantinsuyu 1: 11-17.

MITCHELL, T.

1988 Colonising Egypt. Cambridge: Cambridge University Press.

MORRIS, C., \& THOMPSON, D.

1985 Huánuco Pampa: An Inka City and its Hinterland. London: Thames and Hudson.

MURRA, J. V.

1980 [1956] The Economic Organization of the Inka State. Greenwich, Conn.: JAI Press.

NAIR, S. E.

2003 Of Remembrance and Forgetting: The Architecture of Chinchero, Peru from Thupa Inka to the Spanish Occupation. Unpublished Ph.D. Dissertation, University of California, Berkeley.

NILES, S. A.

1980 «Pumamarca: A Late Intermediate Site near Ollantaytambo.» Ñawpa Pacha 18: 49-62.

1987a Callachaca: Style and Status in an Inka Community. Iowa City: University of Iowa Press.

$1987 b$ «Niched Walls in Inka Design.» Journal of the Society of Architectural Historians, 46(3): 277-285.

1988 «Looking for 'Lost' Inka Palaces.» Expedition 30(3): 56-64.

1999 The Shape of Inka History: Narrative and Architecture in an Andean Empire. Iowa City: University of Iowa Press.

OGBURN, D.

2005 «Dynamic Display, Propaganda, and the Reinforcement of Provincial Power in the Inka Empire.» Archaeological Papers of the American Anthropological Association 14: 225-239.

PARDO, L. A.

1938 «Hacia una nueva clasificación de la cerámica Cuzqueña del antiguo imperio de los Inkas.» Revista del Instituto Arqueológico del Cusco 3: 4-5.

PAREDES, M.

2003 «Practicas funeraria inkaicas en Sacsayhuaman: enterramientos ceremoniales y complejo funerario». En: G. Urton y I. Farrington (eds.), Identidad y Transformacion en el Tawantinsuyu y en los Andea Coloniales: Perspectivas Arqueologicas y Etnohistoricas, Segunda Parte. Lima: Boletin de Arqueología PUCP № 7: 79-112.

PIZARRO, P.

1965 [1571] «Relación del descubrimiento y conquista de los reinos del Perú,» En: Biblioteca de Autores Españoles V. 168, pp. 162-242. Madrid: Ediciones Atlas. 
POLO DE ONDEGARDO, J. D.

1916 [1571] «Informaciones acerca de la religion y gobierno de los inkas (1a. parte),» En: Coleccion de Libros y Documentos Referentes a la Historia del Peru, serie 1, tomo 3, pp. 3-208. Lima: Imprenta y Libreria Sanmarti y Ca.

PROTZEN, J.-P.

1985 «Inka Quarrying and Stonecutting.» JSAH, XLIV(May), 161-182.

1986 «Inka Stonemasonry.» Scientific American, 254(2): 94-105.

1991 Inka Architecture and Construction at Ollantaytambo. New York: Oxford University Press.

2000 «Inka Architecture.» En: L. Minelli (ed.), The Inka World: the Development of Precolumbian Peru, A.D. 1000-1534: 193-217. Norman: University of Oklahoma Press.

RAMÍREZ, S. E.

2005 To Feed and be Fed: The Cosmological Bases of Authority and Identity in the Andes. Stanford: Stanford University Press.

RENFREW, C.

1976 «Megaliths, territories and populations.» En: S. J. De Laet (ed.), Acculturation and Continuity in Atlantic Europe: 198-220. Bruges: De Tempel.

ROSTWOROWSKI DE DIEZ CANSECO, M.

1962 «Nuevos datos sobre tenencia de tierras reales en el inkario». Revista del Museo Nacional 31: 130159.

1978 «Una hipótesis sobre el surgimiento del estado inka.» En: M. M. Ramiro (ed.), Actas y trabajos del III congreso peruano «El hombre y la cultura andina: 89-100. Lima: UNMSM.

ROWE, J. H.

1944 An Introduction to the Archaeology of Cusco. Cambridge: Harvard University.

1945 «Absolute Chronololgy in the Andean Area». American Antiquity 10(3): 265-284.

1946 «Inka Culture at the Time of Spanish Conquest.» En: J. Steward (ed.), Handbook of South American Indians, vol. 2: The Andean Civilizations: 183-330. Washington D.C.: U.S. Government Printing Office.

1967 «What Kind of a Settlement was Inka Cusco?» Nawpa Pacha 5: 59-76.

1985 «La constitución Inka del Cusco». Histórica 9(1): 35-73.

1997 «Las tierras reales de los inkas.» En: R. Varón y J. Flores (eds.) Arqueología, antropología, y historia en los Andes: 277-287. Lima: IEP.

SALOMON, F.

1991 «Introduction.» En: F. Salomon y J. Urioste (eds.) The Huarochirí Manuscript: A Testament of Ancient and Colonial Andean Religion. Austin: University of Texas Press.

SARMIENTO DE GAMBOA, P.

1965 [1572] Historia de los Inkas. Biblioteca de Autores Españoles v. 135. Madrid: Ediciones Atlas.

SCOTT, J. C.

1998 Seeing like a State: How Certain Schemes to Improve the Human Condition have Failed. New Haven: Yale University Press.

SHARMA, C. L.

1993 Ruling Elites of Rajasthan: A Changing Profile. New Delhi: MD Publications.

SMITH, A. T.

2003 The Political Landscape: Constellations of Authority in Early Complex Polities. Berkeley: University of California Press.

SOTO H. M. y CABRERA C. D.

1999 Arquitectura Inca en Ollantaytambo: Registro Descripción y analisis Tecnico - Morfológico del Area Urbana de un Tambo Inca. Tesis, Facultad de Ciencias Sociales, Cusco: Universidad de San Antonio Abad del Cusco. 


\section{VALCÁRCEL, L.}

1934 «Los trabajos arqueológicos en el Departamento de Cusco. Sajsawaman Reduscubierto I-II.» Revista del Museo Nacional, 3, 3-36, 211-233.

1935 «Los trabajos arqueológicos en el Departamento de Cusco. Sajsawaman Reduscubierto III-IV». Revista del Museo Nacional, 4, 1-24, 161-203.

VALENCIA ZEGARRA, A., \& GIBAJA OVIEDO, A.

1992 Machu Picchu: La investigacion y conservacion del monumento arqueologico despues de Hiram Bingham. Cusco: Municipalidad de Qosqo.

VERA, L.

1986 Informe Arqueológico, Inkamisana y Andén. Cusco: INC.

WERNKE, S. A.

2003 An Archaeo-History of Andean Community and Landscape: The Late Pre-Hispanic and Early Colonial Colca Valley, Peru. Unpublished Ph.D. Dissertation, University of Wisconsin, Madison.

2006a «Collagua 'Eco-logistics': Intermediate Elites and Hybrid Community Structures in the Colca Valley, Peru.» En: C. M. Elson y R. A. Covey (eds.), Intermediate Elites in Pre-Columbian States and Empires: 175-211. Tucson: University of Arizona Press.

2006b «The Politics of Community and Inka Statecraft in the Colca Valley, Peru». Latin American Antiquity: 17: 177-208.

2013 Negotiated Settlements: Andean Communities and Landscapes under Inka and Spanish Colonialism. Gainesville: University Press of Florida.

YAMAMOTO, N.

1985 «The ecological complementarity of agro-pastoralism: Some comments.» En: S. Masuda, I. Shimada, y C. Morris (eds.). Andean Ecology and Civilization: 85-100. Tokyo: University of Tokyo Press. 